\title{
Pyclen-Based Ligands Bearing Pendant Picolinate Arms for Gadolinium Complexation
}

\author{
Gwladys Nizou, ${ }^{\dagger}$ Enikő Molnár, ${ }^{\ddagger}$ Nadège Hamon, ${ }^{\dagger}$ Ferenc Krisztián Kálmán, ${ }^{\ddagger}$ Olivier \\ Fougère,,$^{\S}$ Olivier Rousseaux, ${ }^{\S}$ David Esteban Gòmez, ${ }^{\perp}$ Carlos Platas-Iglesias, ${ }^{\perp}$ Maryline \\ Beyler, ${ }^{* \dagger}$ Gyula Tircsó ${ }^{* \neq}$ and Raphaël Tripier*,† \\ † Univ. Brest, UMR-CNRS 6521 CEMCA, 6 avenue Victor le Gorgeu, 29238 BREST, France. \\ ‡ Department of Physical Chemistry, Faculty of Science and Technology, University of Debrecen, \\ Egyetem tér 1, H-4032 Debrecen, Hungary \\ § Groupe Guerbet, Centre de Recherche d'Aulnay-sous-Bois, BP 57400, 95943 Roissy CdG Cedex, France \\ ${ }^{\perp}$ Centro de Investigacións Científicas Avanzadas (CICA) and Departamento de Química, Universidade \\ da Coruña, Campus da Zapateira-Rúa da Fraga 10, 15008 A Coruña, Spain \\ *E-mail: raphael.tripier@univ-brest.fr (R. T.) \\ *E-mail: gyula.tircso@science.unideb.hu (Gy. T.) \\ *E-mail: Maryline.Beyler@univ-brest.fr (M.B.)
}

\section{Summary}

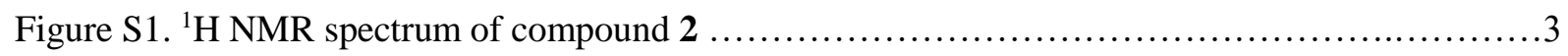



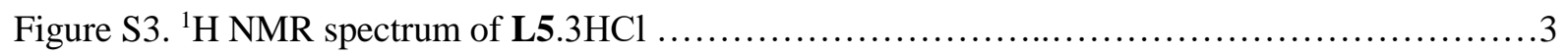

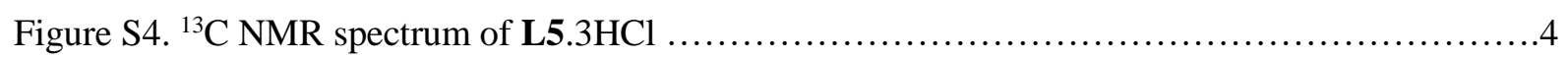

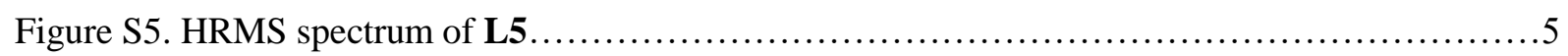

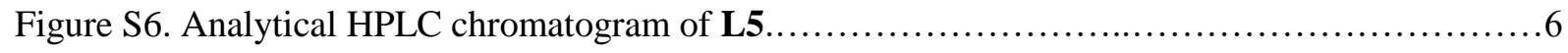

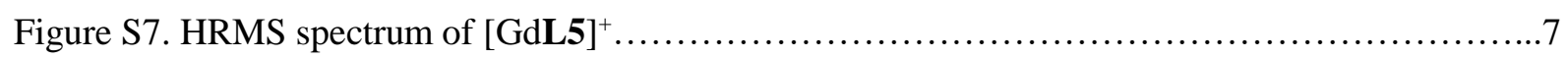

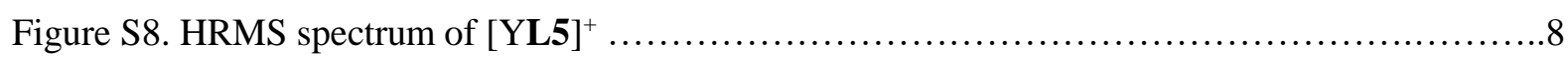

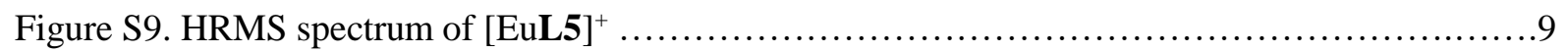

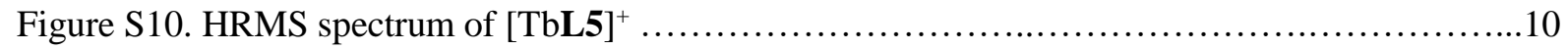

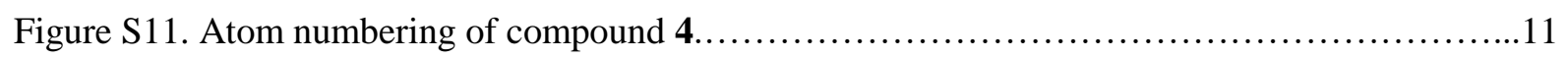

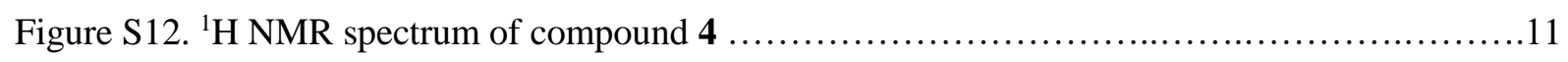

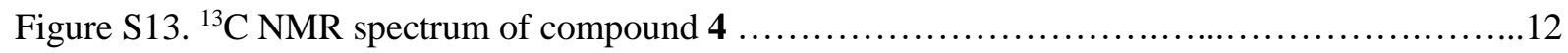

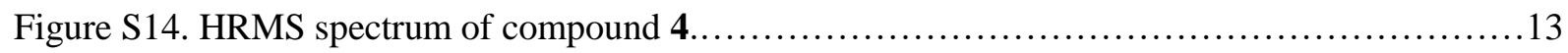

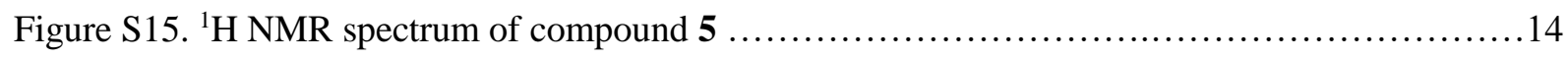

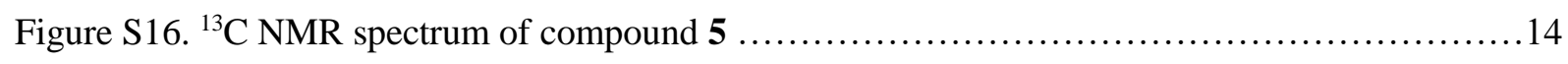

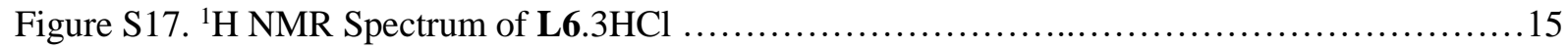

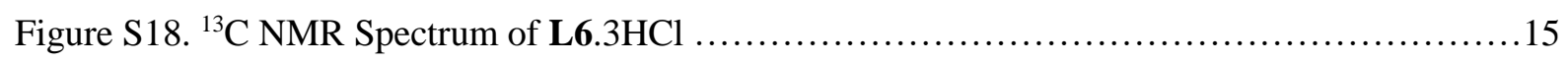




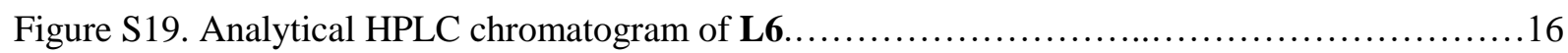

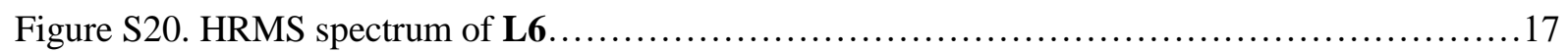

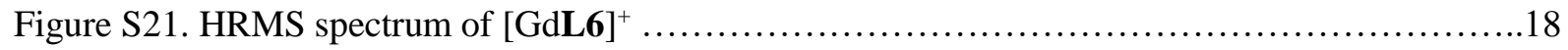

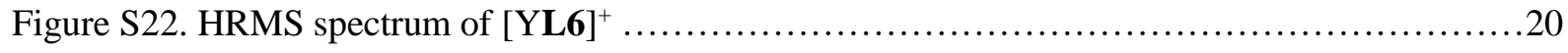

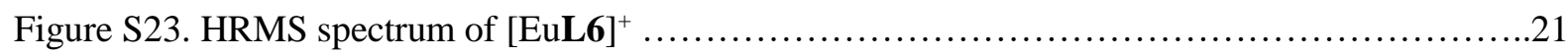

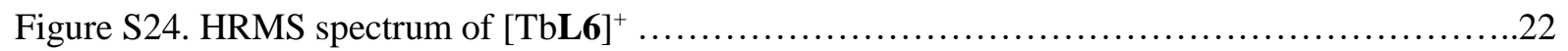

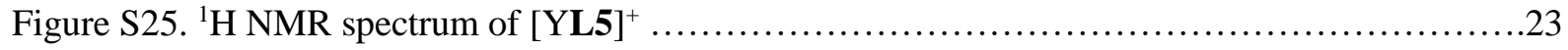

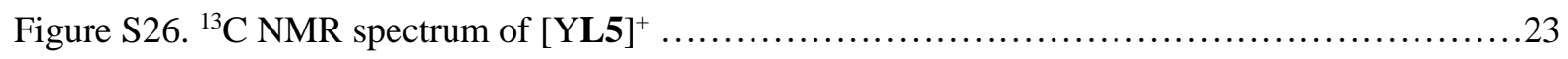

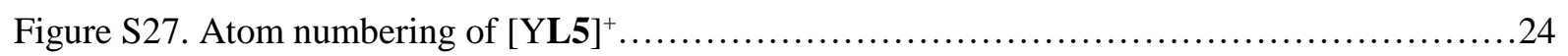

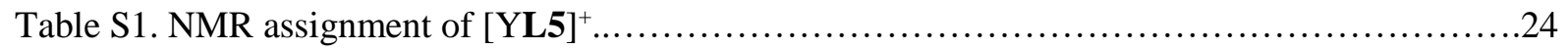

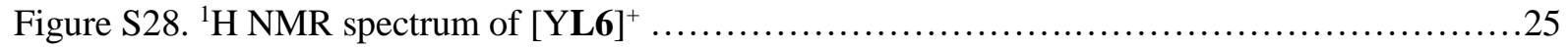

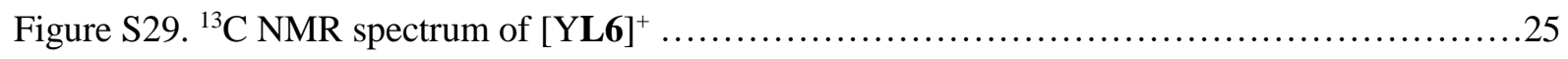

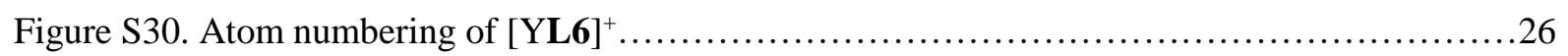

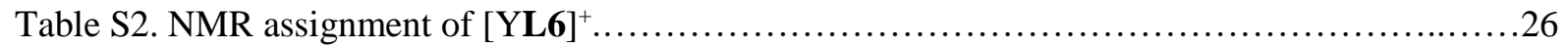

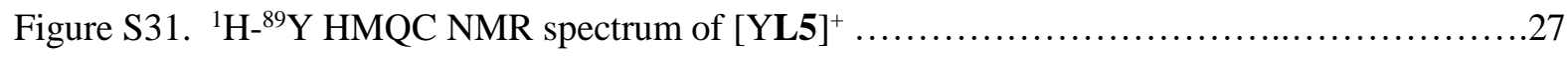

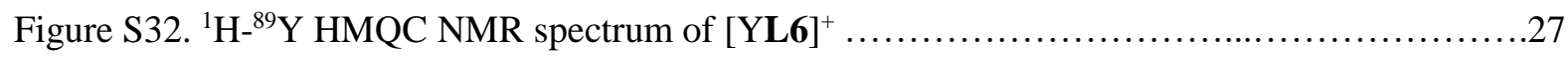

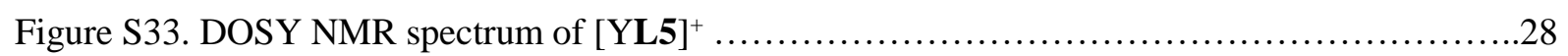

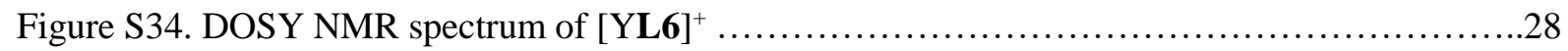

Figure S35. Absorption spectra of the $[\mathrm{LnL5}]^{+}$and $[\mathbf{L n L 6}]^{+}$complexes $(\operatorname{Ln}=\mathrm{Eu}, \mathrm{Tb}) \ldots \ldots \ldots \ldots \ldots . .29$

Figure S36. Emission decay profiles recorded in $\mathrm{H}_{2} \mathrm{O}$ and $\mathrm{D}_{2} \mathrm{O}$ solutions of the [EuL5] ${ }^{+}$complex.....30

Figure S37. Emission decay profiles recorded in $\mathrm{H}_{2} \mathrm{O}$ and $\mathrm{D}_{2} \mathrm{O}$ solutions of the [EuL6] ${ }^{+}$complex ....31

Figure S38. Emission decay profiles recorded in $\mathrm{H}_{2} \mathrm{O}$ and $\mathrm{D}_{2} \mathrm{O}$ solutions of the $[\mathbf{T b} \mathbf{L 5}]^{+}$complex ....32

Figure S39. Emission decay profiles recorded in $\mathrm{H}_{2} \mathrm{O}$ and $\mathrm{D}_{2} \mathrm{O}$ solutions of the $[\mathrm{TbL6}]^{+}$ complex.

Figure S40. Longitudinal relaxation rate of water proton nuclei measured from aqueous solutions of the $[\text { GdL5 }]^{+}$complex . .34

Figure S41. Longitudinal relaxation rate of water proton nuclei measured from aqueous solutions of the $[\text { GdL6] }]^{+}$complex. .34

Figure $\mathrm{S} 42$. Structures of the $\left[\mathrm{Gd} \mathbf{L 5}\left(\mathrm{H}_{2} \mathrm{O}\right)\right]^{+} \cdot 2 \mathrm{H}_{2} \mathrm{O}$ and $\left[\mathrm{Gd} \mathbf{L 6}\left(\mathrm{H}_{2} \mathrm{O}\right)\right]^{+} \cdot 2 \mathrm{H}_{2} \mathrm{O}$ systems obtained with DFT calculations and bond distances of the metal coordination

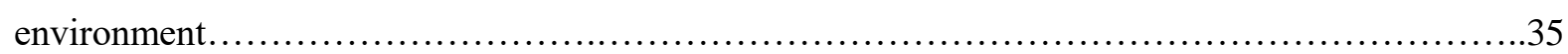

Table S3. Cartesian coordinates $(\AA)$ of the $\left[\operatorname{GdL5}\left(\mathrm{H}_{2} \mathrm{O}\right)\right]^{+} \cdot 2 \mathrm{H}_{2} \mathrm{O}$ system optimized with DFT

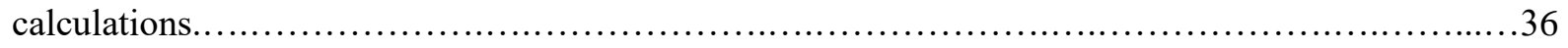

Table S4. Cartesian coordinates $(\AA)$ of the $\left[\operatorname{GdL6}\left(\mathrm{H}_{2} \mathrm{O}\right)\right]^{+} \cdot 2 \mathrm{H}_{2} \mathrm{O}$ system optimized with DFT calculations. 


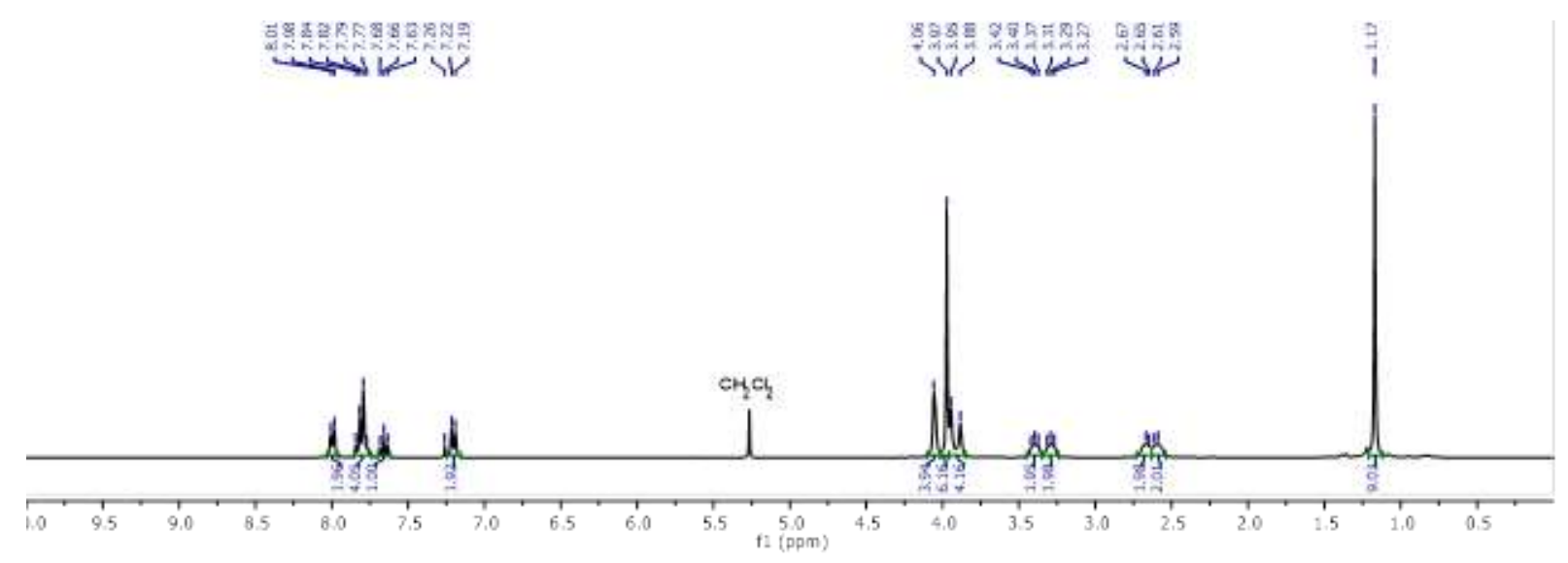

Figure S1. ${ }^{1} \mathrm{H}$ NMR spectrum of compound 2 in $\mathrm{CDCl}_{3}$ at $300 \mathrm{MHz}, 298 \mathrm{~K}$.

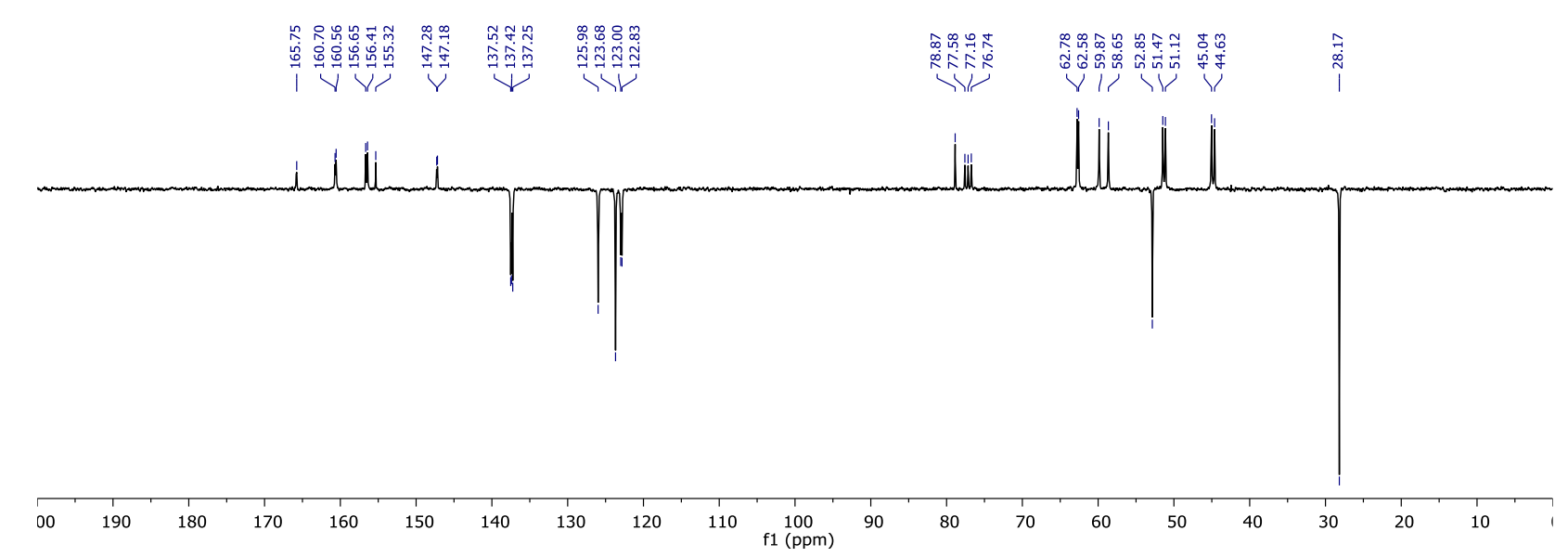

Figure S2. ${ }^{13} \mathrm{C}$ NMR spectrum of compound 2 in $\mathrm{CDCl}_{3}$ at $75 \mathrm{MHz}, 298 \mathrm{~K}$.

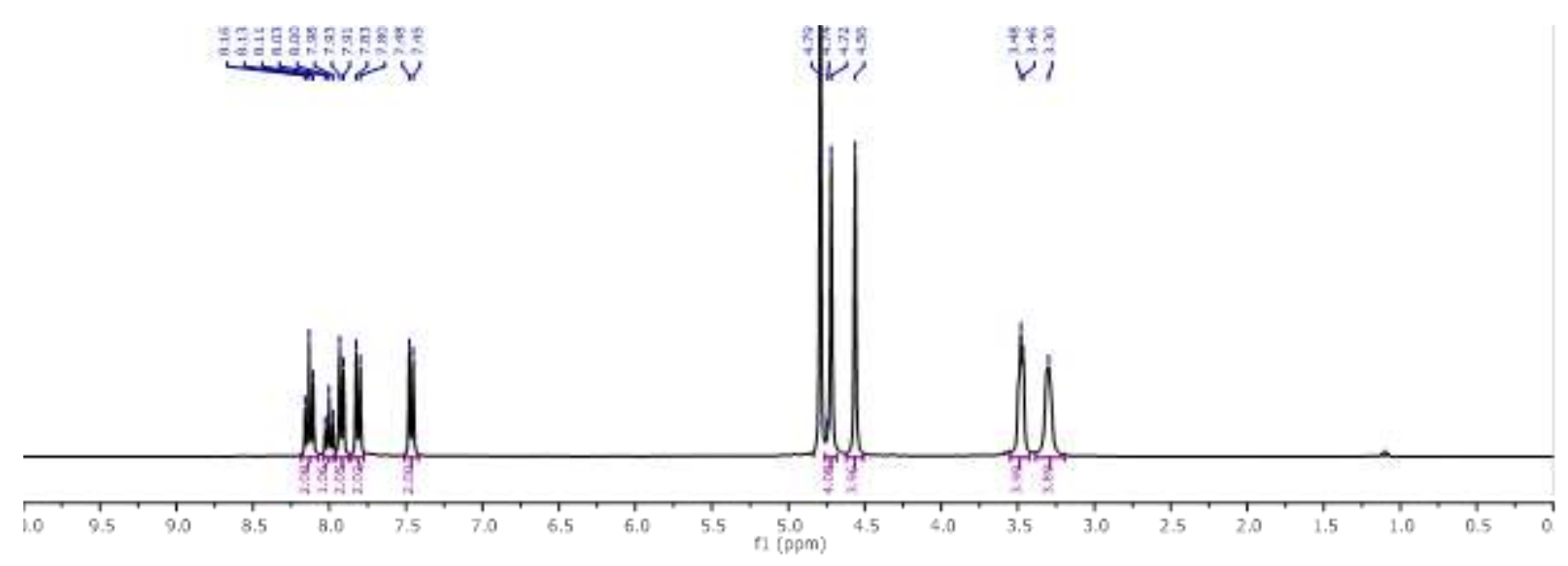

Figure S3. ${ }^{1} \mathrm{H}$ NMR spectrum of $\mathbf{L 5 . 3} \mathrm{HCl}$ in $\mathrm{D}_{2} \mathrm{O}$ at $300 \mathrm{MHz}, 298 \mathrm{~K}$. 


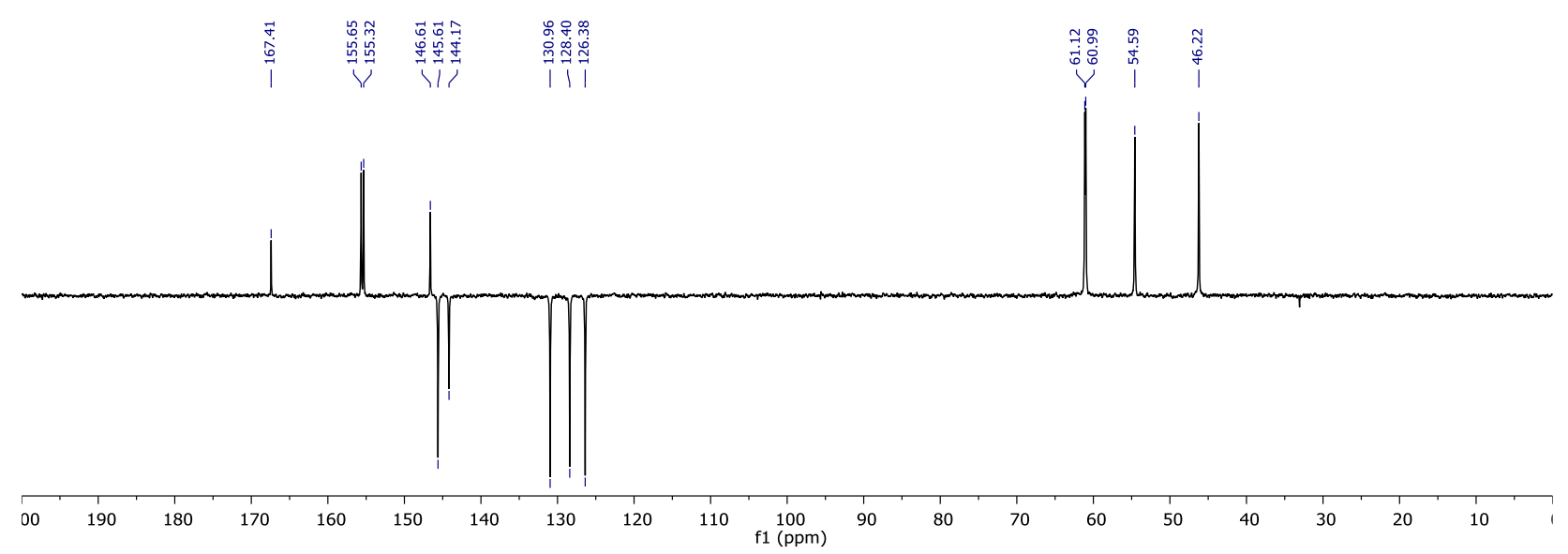

Figure S4. ${ }^{13} \mathrm{C}$ NMR Spectrum of $\mathbf{L 5 . 3} \mathrm{HCl}$ in $\mathrm{D}_{2} \mathrm{O}$ at $75 \mathrm{MHz}, 298 \mathrm{~K}$. 
Analysis info

Sample Name 710-150 Pc2Pa sym

Analysis Name X038175CYC.d

Acquisition Date

Instrument/Serk

Method

02/11/2017 12:30:29

maXis 255552.00086

Positif.m

Acquisition Parameter

Source Type ES!

Scas Begin $\quad 50 \pi / 2$

$2500 \mathrm{~m} / \mathrm{z}$

Ion Polarity

Set Capillary

$1800.0 \mathrm{Vpp}$
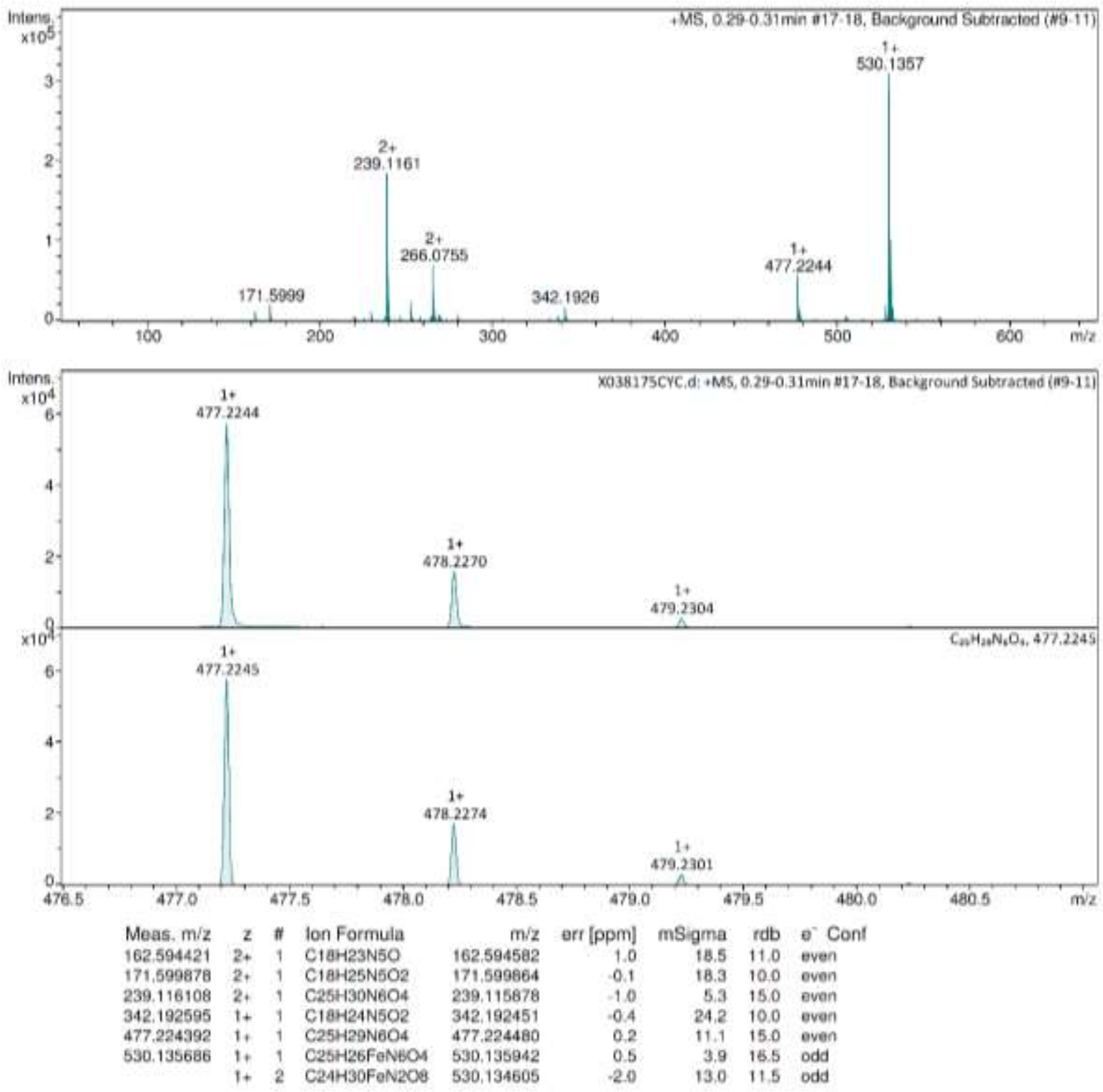

Figure S5. HRMS spectrum of $\mathbf{L 5}$. 
mv

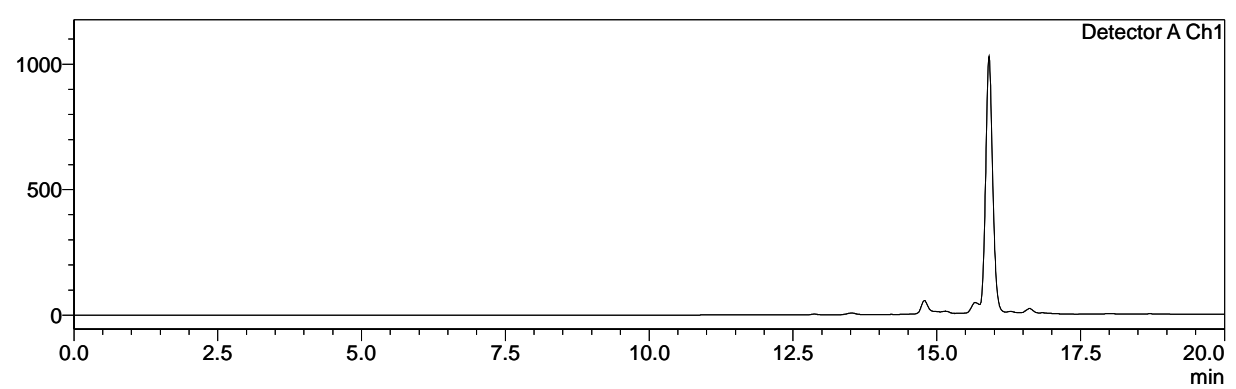

Figure S6. Analytical HPLC chromatogram of $\mathbf{L 5}$ (Gradient: $100 \% \mathrm{H}_{2} \mathrm{O}+0.1 \%$ TFA 0 to 5 min, 0 to $80 \% \mathrm{MeOH} 5$ to $15 \mathrm{~min}, 80 \% \mathrm{MeOH} 15$ to $17 \mathrm{~min}, 80$ to $0 \% \mathrm{MeOH} 17$ to $18 \mathrm{~min}, 100 \% \mathrm{H}_{2} \mathrm{O}+0.1 \%$ TFA 18 to $20 \mathrm{~min}$. Flow : $1 \mathrm{~mL} / \mathrm{min}$. retention time $=15.907 \mathrm{~min}$. + detector $=254 \mathrm{~nm}$ ). 
Analysis Info

Sample Name Analysis Name
787-143 Gd-Pcpa-sym X050007CYC.d
Acquisition Date Instrument/Ser\# Method
17/04/2019 11:38:11 maXis 255552.00086 positif-6.m

\section{Acquisition Parameter}

Source Type ESI

Scan Begin $\quad 50 \mathrm{~m} / \mathrm{z}$

Ion Polarity Positive

Set Capilary $\quad 4500 \mathrm{~V}$

Set Collision Cell AF $12000 \mathrm{Vpp}$

Set Dry Heater

set Dry Gas $\quad 7.0 \mathrm{l}$ limin
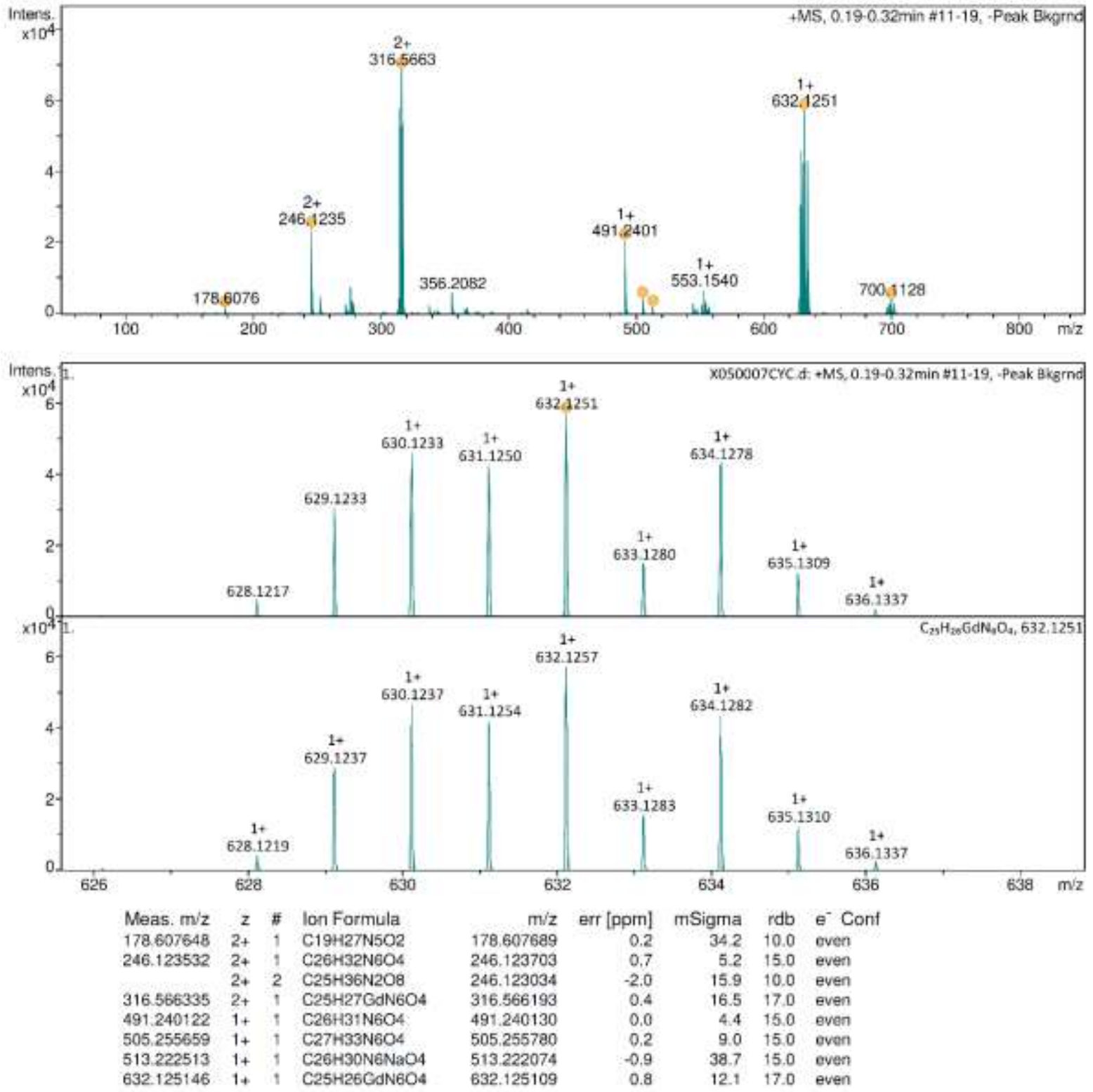

Figure S7. HRMS spectrum of $[\mathrm{GdL5}]^{+}$. 


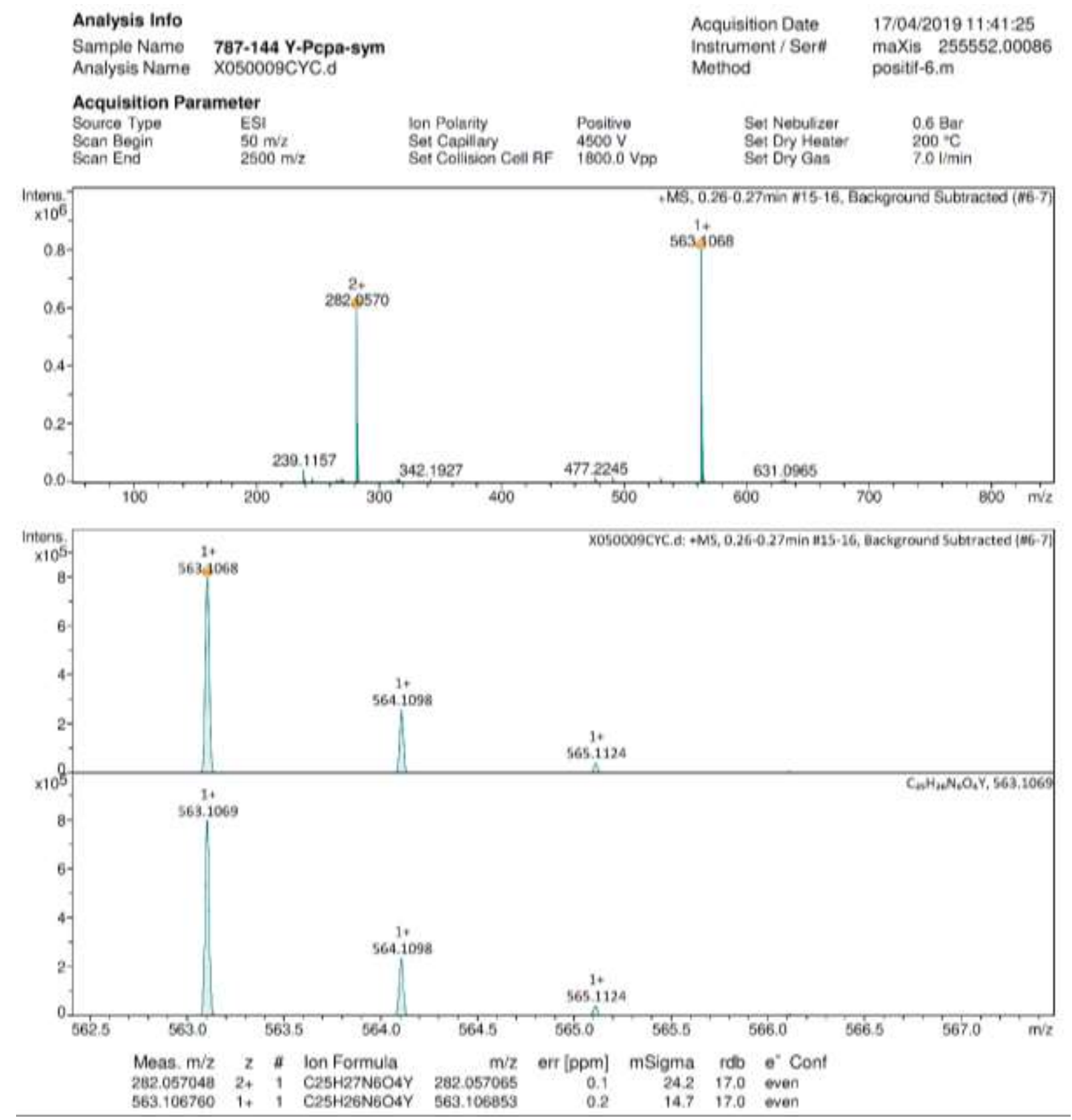

Figure S8. HRMS spectrum of $[\text { YL5 }]^{+}$. 
Analysis Info

Sample Name 788-003 Eu-Pc2pa-sym

Analysis Name X053872CYC.d

Acquisition Date

instrument/Ser\#

Method

$11 / 12 / 2019: 18: 24: 34$

maXis 255552.00086

Positif.m

Acquisition Parameter

Source Type ES!

Scan Begin

50

$2500 \mathrm{~m} / \mathrm{z}$

Ion Polarity

Set Capillay

Set Collision Cell RF

Postive

4500 V

$1800.0 \mathrm{Vpp}$


Figure S9. HRMS spectrum of $[\mathrm{EuL5}]^{+}$. 
Acquisition Date Instrument/Serk

Method

$11 / 12 / 201918: 23: 04$ $\operatorname{maXis} \quad 255552,00086$

Positif.m

Acquisition Parameter

$\begin{array}{ll}\text { Source Type } & \text { ESI } \\ \text { Scan Begin } & 50 \mathrm{~m} / \mathrm{z}\end{array}$

$\begin{array}{ll}\text { Scan Begin } & 50 \mathrm{~m} / \mathrm{z} \\ \text { Scan End } & 25000 \mathrm{~m} / \mathrm{z}\end{array}$

Ion Polarity Positive

Set Capiliary $\quad 4500 \mathrm{~V}$

Set Colision Cell RF 1800.0 Vpp

$\begin{array}{ll}\text { Set Nebulizer } & 0.6 \mathrm{Bar} \\ \text { Set Dry Heater } & 200 \text { "C } \\ \text { Set Dry Gas } & 7.0 \mathrm{Vmir}\end{array}$

+MS, 0.31 min 818 , Background Subtracted (N4-6)
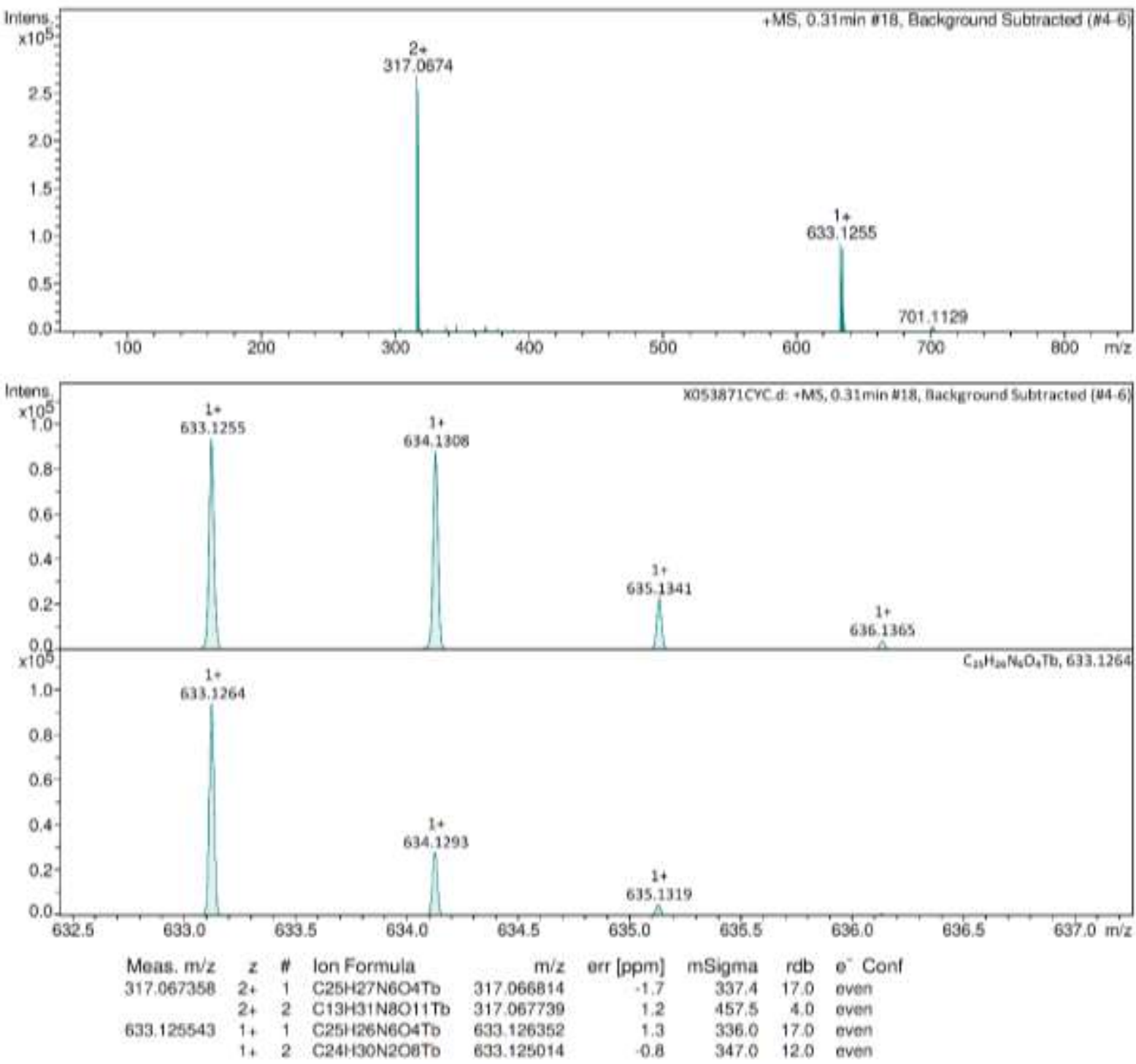

Figure S10. HRMS spectrum of [TbL5] $]^{+}$. 


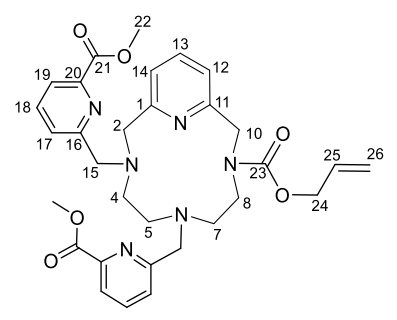

Figure S11. Atom numbering of compound 4.

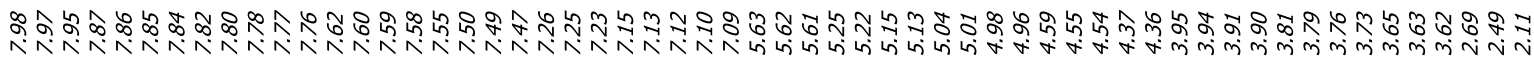

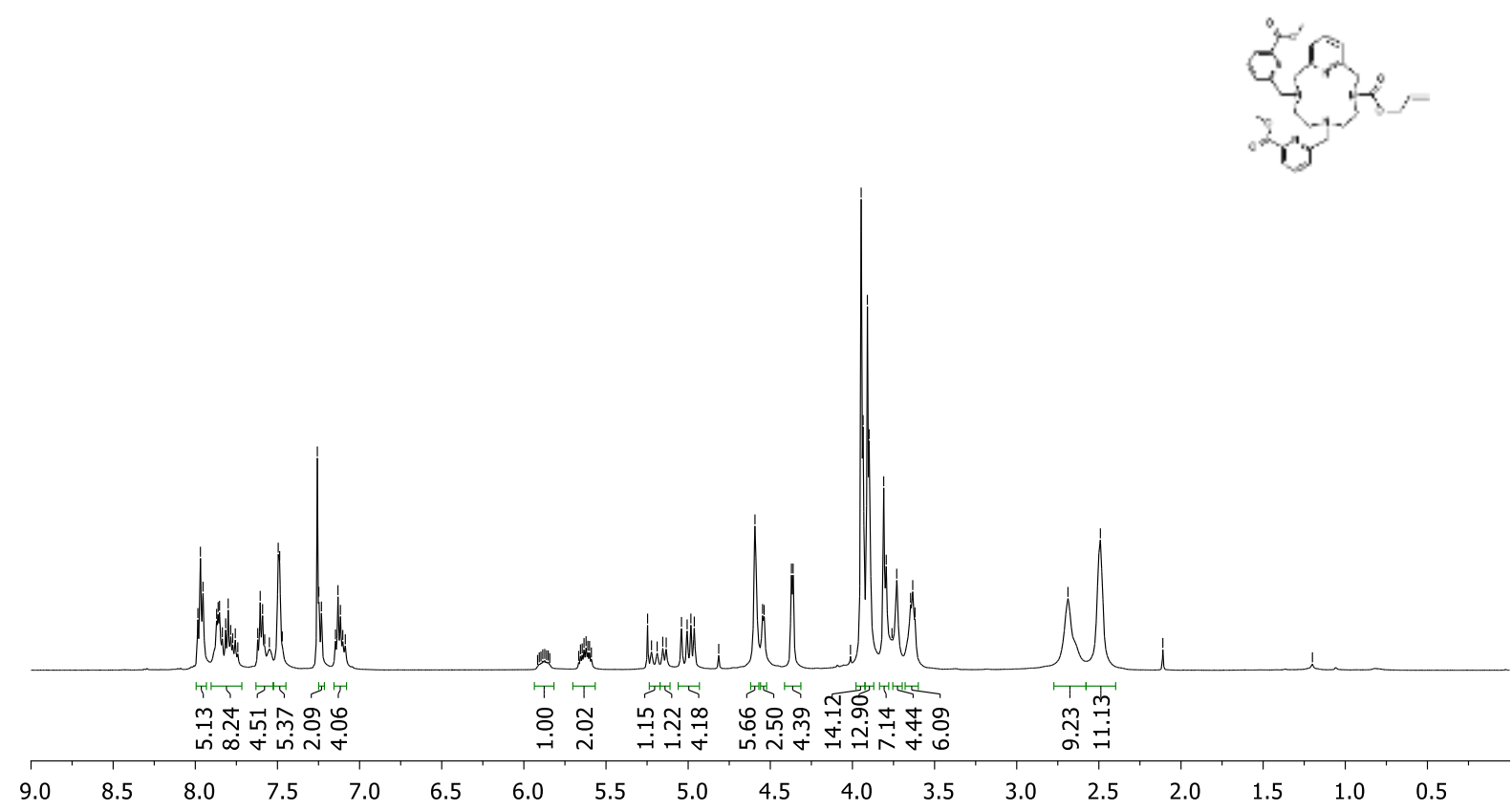

Figure S12. ${ }^{1} \mathrm{H}$ NMR spectrum of compound 4 in $\mathrm{CDCl}_{3}$ at $500 \mathrm{MHz}, 298 \mathrm{~K}$. 


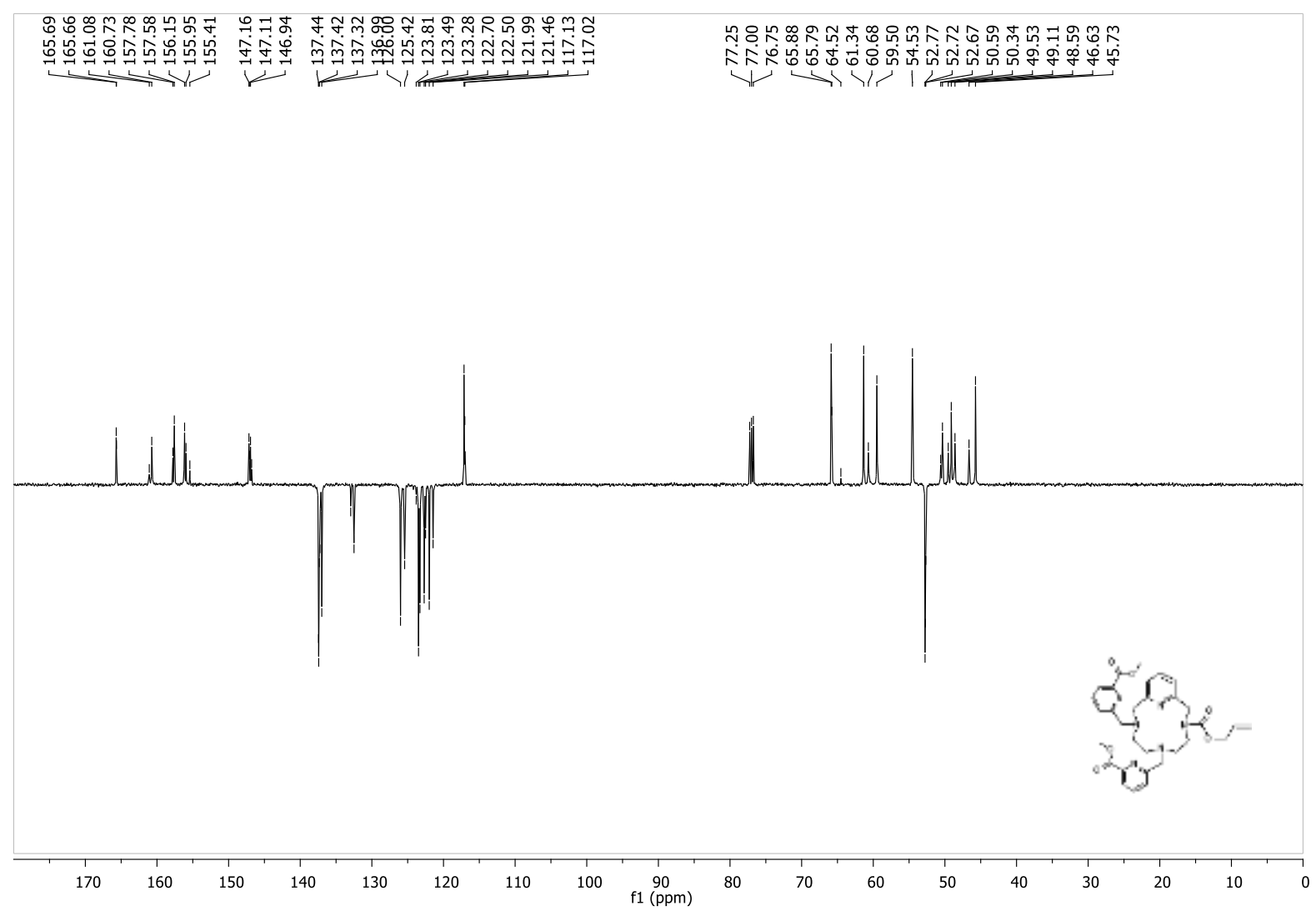

Figure S13. ${ }^{13} \mathrm{C}$ NMR spectrum of compound 4 in $\mathrm{CDCl}_{3}$ at $125 \mathrm{MHz}, 298 \mathrm{~K}$. 


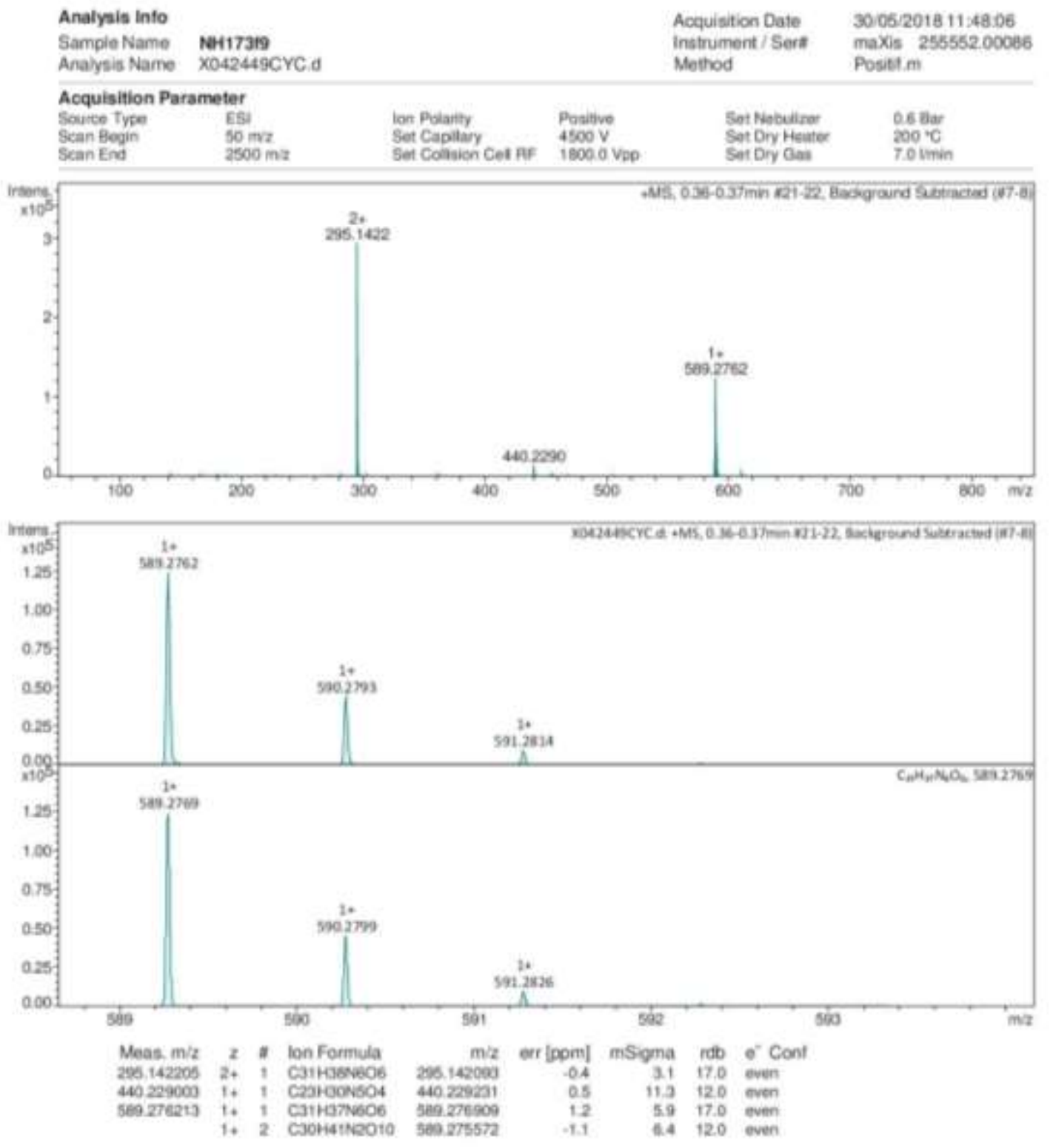

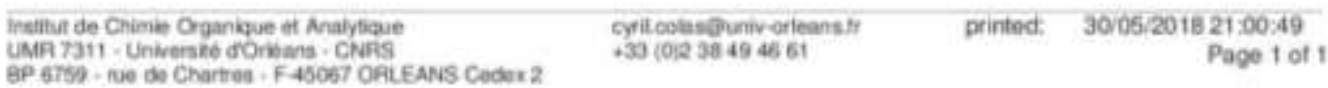

Figure S14. HRMS spectrum of compound 4. 


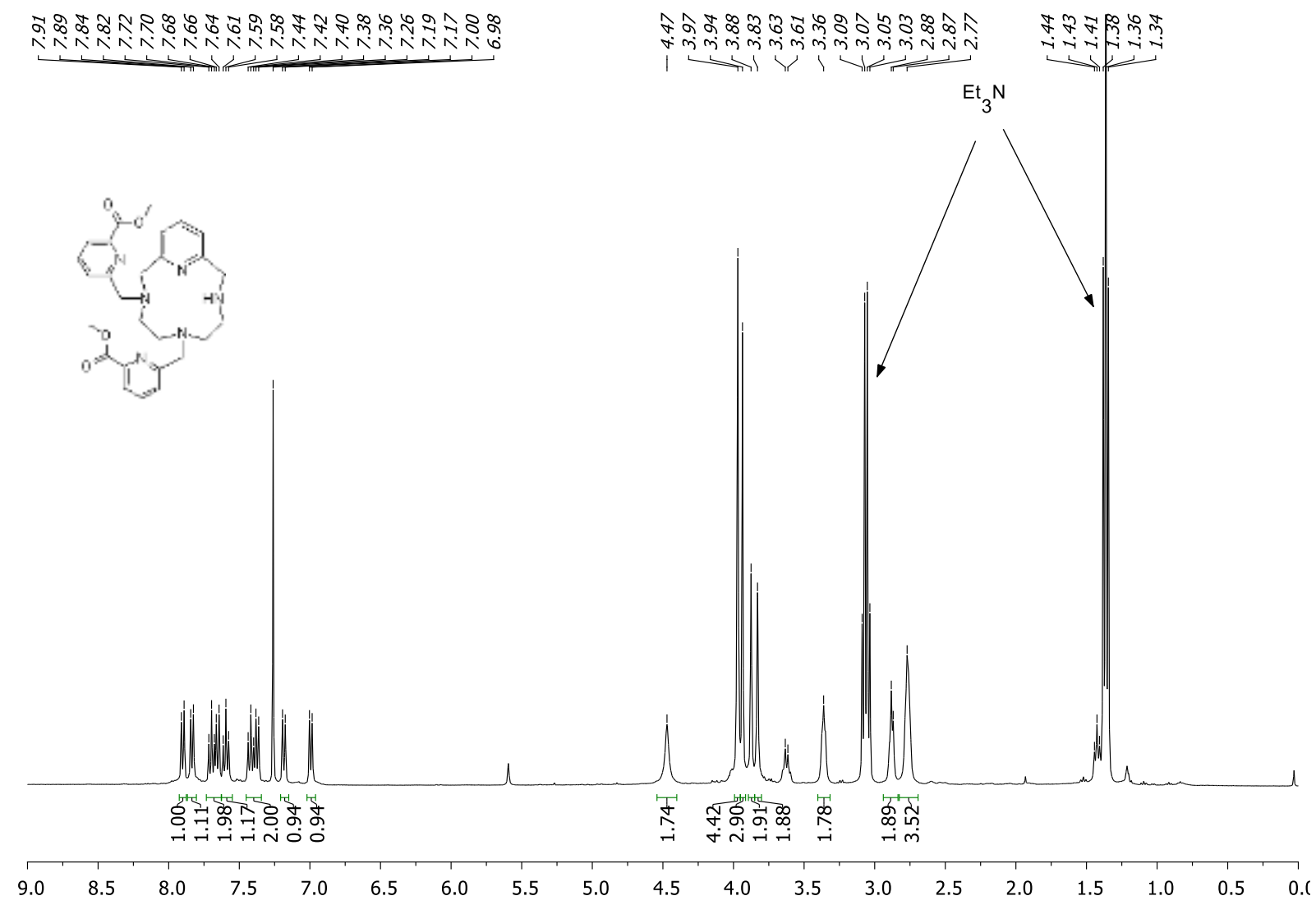

Figure S15. ${ }^{1} \mathrm{H}$ NMR spectrum of compound 5 in $\mathrm{CDCl}_{3}$ at $400 \mathrm{MHz}, 298 \mathrm{~K}$.

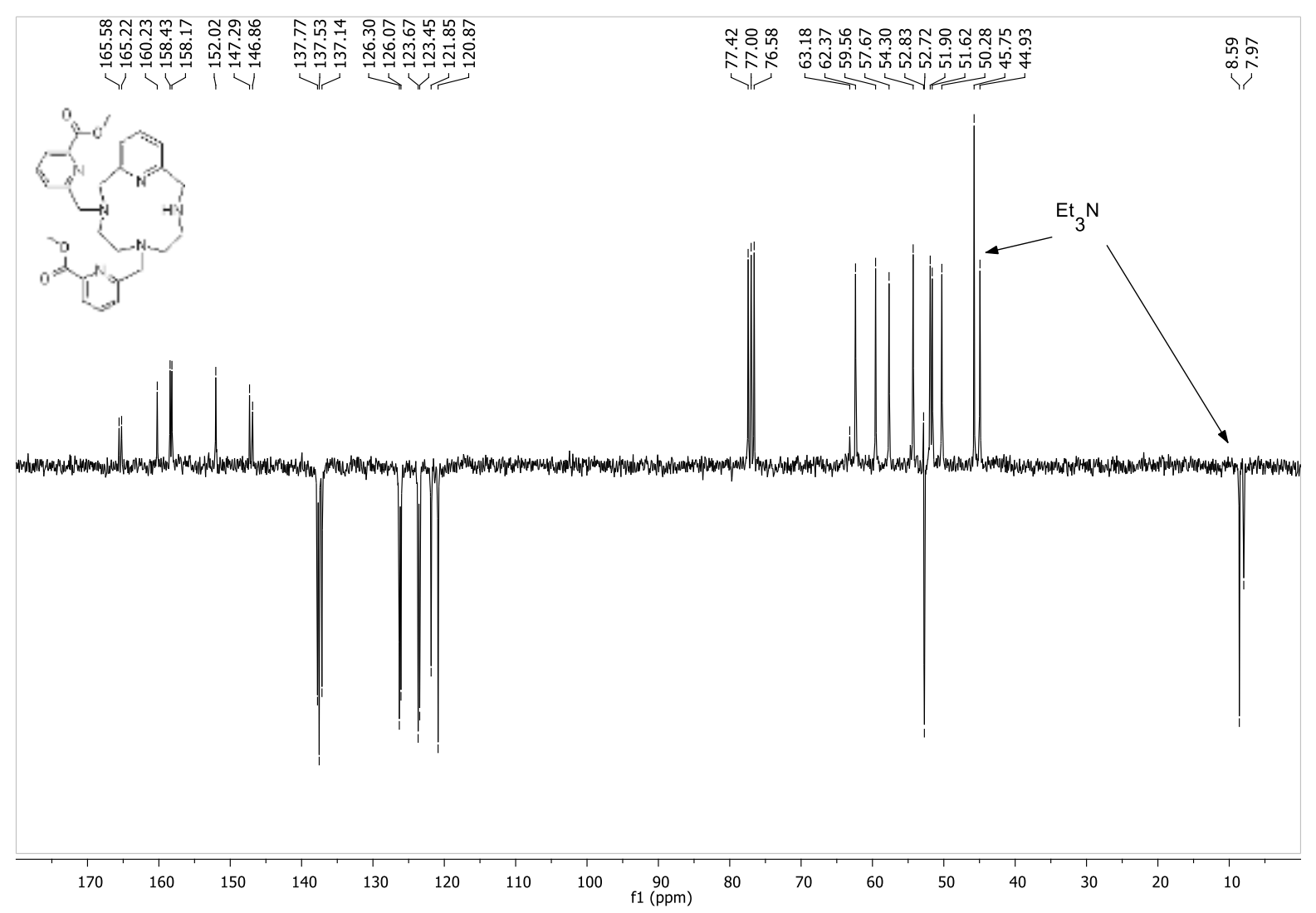

Figure S16. ${ }^{13} \mathrm{C}$ NMR spectrum of compound 5 in $\mathrm{CDCl}_{3}$ at $75 \mathrm{MHz}, 298 \mathrm{~K}$. 


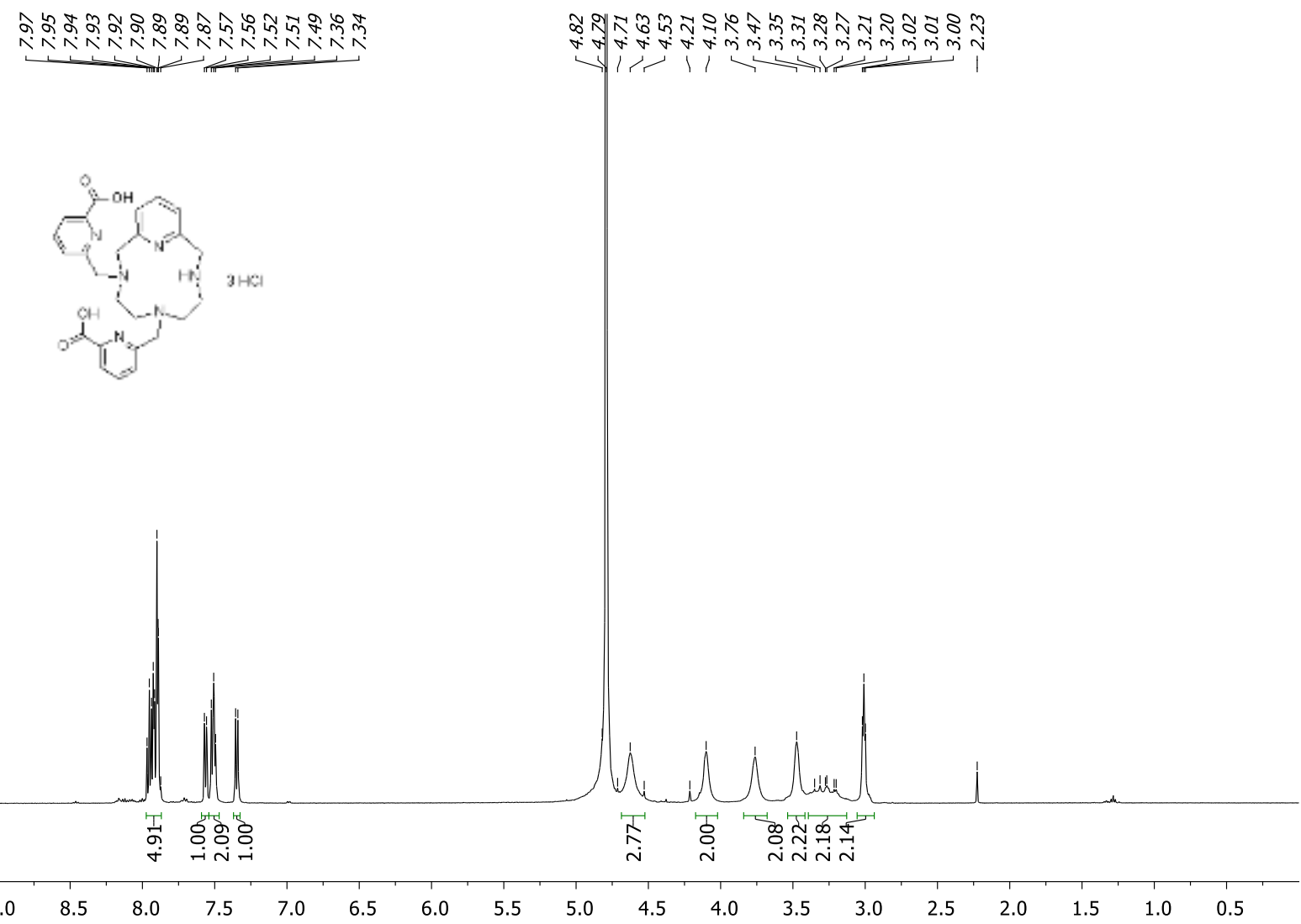

Figure S17. ${ }^{1} \mathrm{H}$ NMR spectrum of $\mathbf{L 6} .3 \mathrm{HCl}$ in $\mathrm{D}_{2} \mathrm{O}$ at $500 \mathrm{MHz}, 298 \mathrm{~K}$.

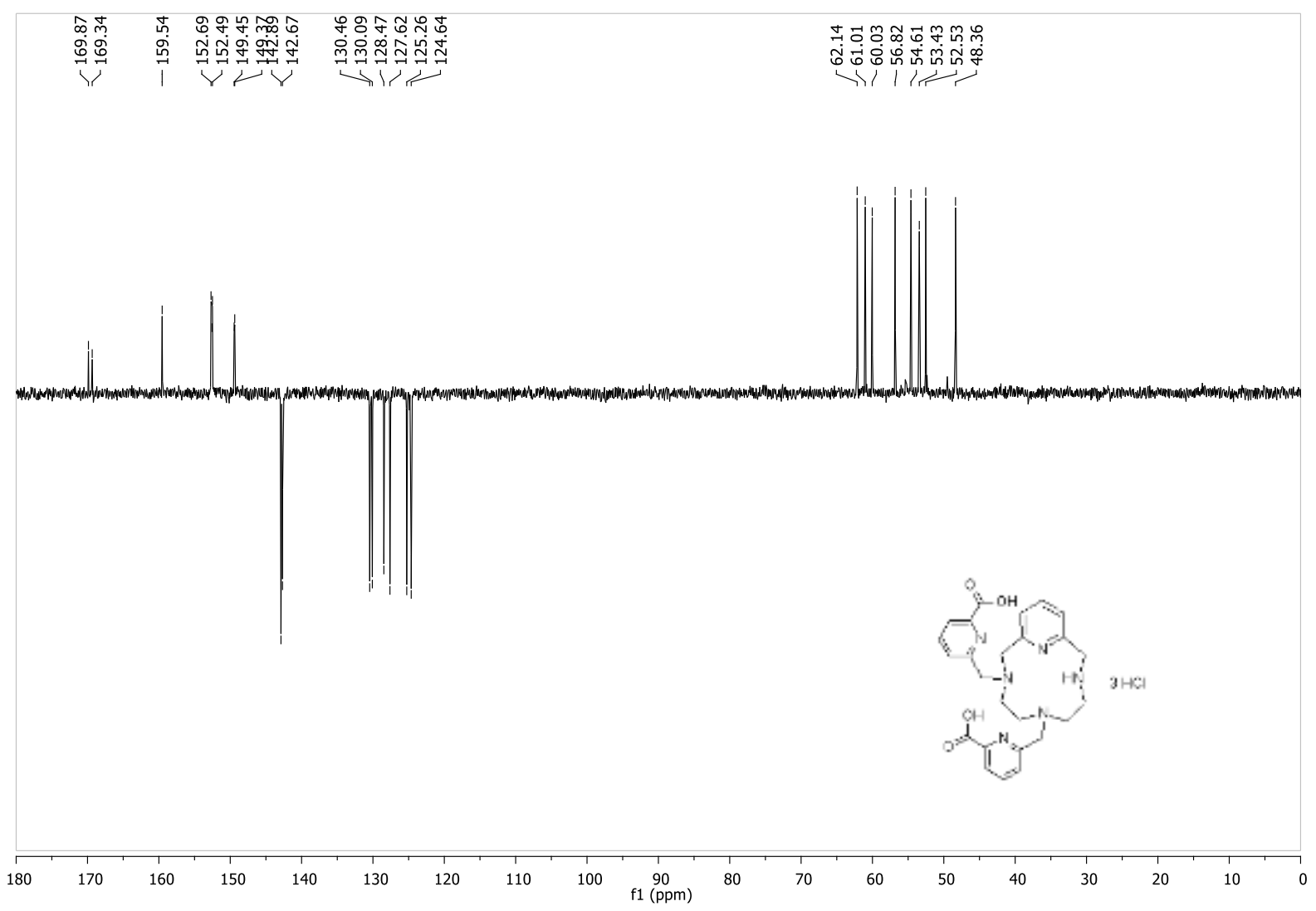

Figure S18. ${ }^{13} \mathrm{C}$ NMR Spectrum of $\mathbf{L 6} .3 \mathrm{HCl}$ in $\mathrm{D}_{2} \mathrm{O}$ at $125 \mathrm{MHz}, 298 \mathrm{~K}$. 
mV

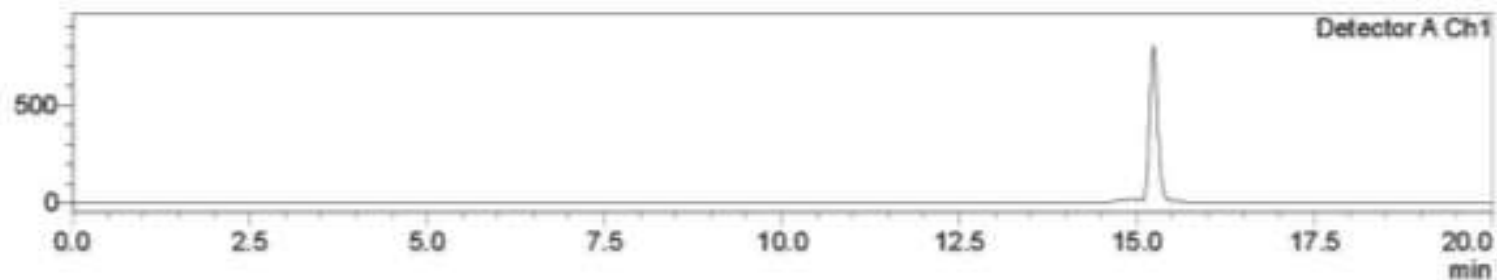

Figure S19. Analytical HPLC chromatogram of L6 (Gradient: $100 \% \mathrm{H}_{2} \mathrm{O}+0.1 \%$ TFA 0 to 5 min, 0 to $80 \% \mathrm{MeOH} 5$ to $15 \mathrm{~min}, 80 \% \mathrm{MeOH} 15$ to $17 \mathrm{~min}, 80$ to $0 \% \mathrm{MeOH} 17$ to $18 \mathrm{~min}, 100 \% \mathrm{H}_{2} \mathrm{O}+0.1 \%$ TFA 18 to $20 \mathrm{~min}$. Flow : $1 \mathrm{~mL} / \mathrm{min}$. retention time $=15.227 \mathrm{~min} .+$ detector $=254 \mathrm{~nm}$ ). 

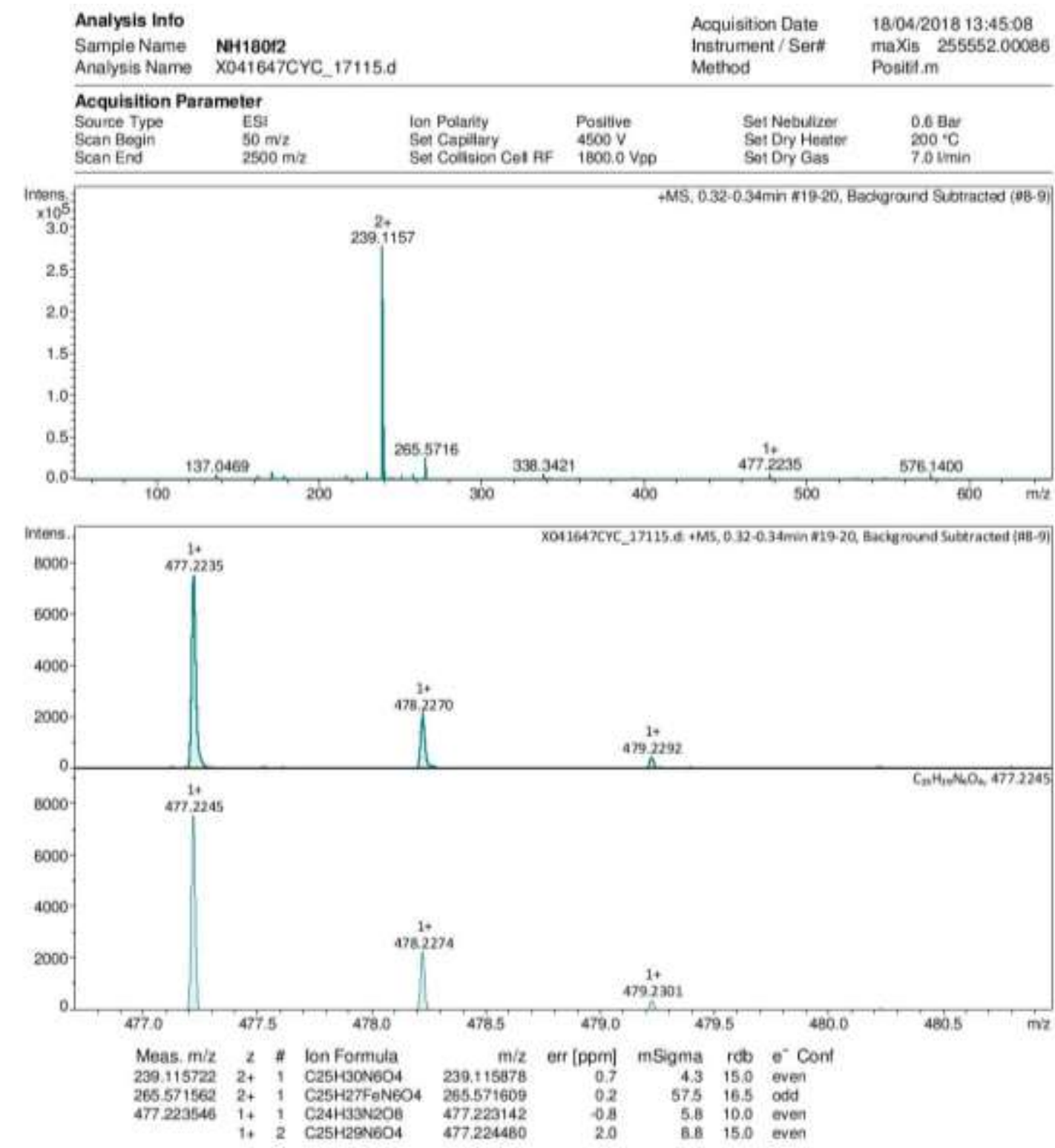

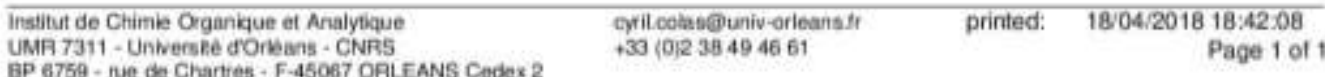

BP 6759 - rue de Chantes - F-45067 OALFANS Codex 2

Figure S20. HRMS spectrum of $\mathbf{L 6}$. 
Analysis Info

Sample Name 787-141 Gd-Pcpa-asym

Analysis Name X050008CYC.d

\section{Acquisition Parameter}

Source Type

Scan Bepin

Scan End

ESI

$50 \mathrm{~m} / 2$

$2500 \mathrm{~m} / \mathrm{z}$

Set Capillary

Set Colasion Cell RF $\quad \begin{aligned} & 4500 \mathrm{~V} \\ & 1800.0 \mathrm{~V}\end{aligned}$

Acquisition Date

Instrument / Sork

Method
17/04/201911:39:49

maxis 255552.00086

positif-6.m
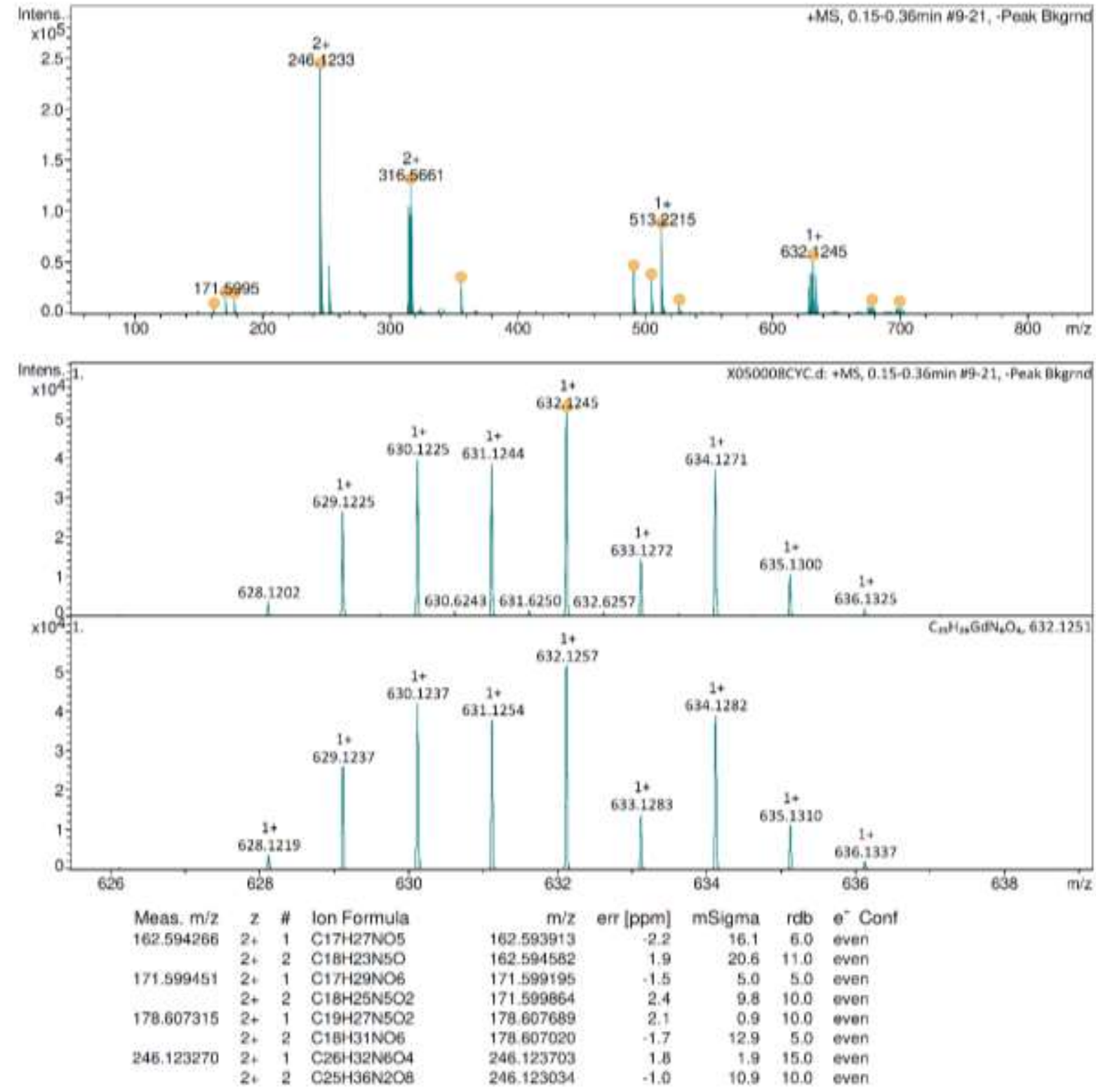


\begin{tabular}{|c|c|c|c|c|c|c|c|c|}
\hline Meas. $m / z$ & $z$ & \# & Ion Formula & $\mathrm{m} / \mathrm{z}$ & err [ppm] & mSigma & $\mathrm{rdb}$ & $\mathrm{e}^{-}$Cont \\
\hline \multirow[t]{2}{*}{316.566091} & $2+$ & 1 & $\mathrm{C} 24 \mathrm{H} 31 \mathrm{GdN} 2 \mathrm{O} 8$ & 316.565524 & -0.9 & 14.3 & 12.0 & even \\
\hline & $2+$ & 2 & $\mathrm{C}_{2} 5 \mathrm{H} 27 \mathrm{GdN} 6 \mathrm{O} 4$ & 316.566193 & 1.2 & 14.6 & 17.0 & even \\
\hline 356.207631 & $1+$ & 1 & $\mathrm{C} 19 \mathrm{H} 26 \mathrm{~N} 5 \mathrm{O} 2$ & 356.208102 & 1.3 & 5.8 & 10.0 & even \\
\hline \multirow[t]{2}{*}{491.239515} & $1+$ & 1 & $\mathrm{C} 26 \mathrm{H} 31 \mathrm{~N} 6 \mathrm{O} 4$ & 491,240130 & 1.3 & 1.0 & 15.0 & even \\
\hline & $1+$ & 2 & $\mathrm{C} 25 \mathrm{H} 35 \mathrm{~N} 2 \mathrm{O} 8$ & 491.238793 & -1.5 & 12.4 & 10.0 & even \\
\hline \multirow[t]{2}{*}{505.255249} & $1+$ & 1 & $\mathrm{C} 27 \mathrm{H} 33 \mathrm{~N} 6 \mathrm{O} 4$ & 505.255780 & 1.1 & 5.0 & 15.0 & even \\
\hline & $1+$ & 2 & $\mathrm{C} 26 \mathrm{H} 37 \mathrm{~N} 2 \mathrm{O} 8$ & 505.254443 & -1.6 & 16.5 & 10.0 & even \\
\hline \multirow[t]{2}{*}{513.221545} & $1+$ & 1 & $\mathrm{C} 26 \mathrm{H} 30 \mathrm{~N} 6 \mathrm{NaO} 4$ & 513.222074 & 1.0 & 1.0 & 15.0 & even \\
\hline & $1+$ & 2 & $\mathrm{C}_{2} 5 \mathrm{H} 34 \mathrm{~N} 2 \mathrm{NaOB}$ & 513.220737 & -1.6 & 12.8 & 10.0 & even \\
\hline \multirow[t]{2}{*}{527.237216} & $1+$ & 1 & $\mathrm{C} 27 \mathrm{H} 32 \mathrm{~N} 6 \mathrm{NaO} 4$ & 527.237724 & 1.0 & 4.0 & 15.0 & even \\
\hline & $1+$ & 2 & $\mathrm{C} 26 \mathrm{H} 36 \mathrm{~N} 2 \mathrm{NaO} 8$ & 527.236387 & -1.6 & 11.8 & 10.0 & even \\
\hline \multirow[t]{2}{*}{632.124484} & $1+$ & 1 & $\mathrm{C}_{25} \mathrm{H}_{26 \mathrm{GdN}} 6 \mathrm{O} 4$ & 632.125109 & 1.9 & 19.9 & 17.0 & even \\
\hline & $1+$ & 2 & $\mathrm{C} 24 \mathrm{H} 30 \mathrm{GdN} 2 \mathrm{O} 8$ & 632.123771 & -0.2 & 22.7 & 12.0 & even \\
\hline \multirow[t]{2}{*}{678.129968} & $1+$ & 1 & C26H28GdN606: & 678.130588 & 1.8 & 20.7 & 17.0 & even \\
\hline & $1+$ & 2 & $\mathrm{C}_{2} 5 \mathrm{H} 32 \mathrm{GdN} 2 \mathrm{O} 10$ & 678.129251 & -0.1 & 25.7 & 12.0 & even \\
\hline \multirow[t]{2}{*}{700.112147} & $1+$ & 1 & $\mathrm{C} 26 \mathrm{H} 27 \mathrm{GdN} 6 \mathrm{NaO} 6$ & 700.112532 & 1.4 & 19.6 & 17.0 & even \\
\hline & $1+$ & 2 & $\mathrm{C} 25 \mathrm{H} 31 \mathrm{GdN} 2 \mathrm{NaO} 10$ & 700.111195 & -0.5 & 22.8 & 12.0 & even \\
\hline
\end{tabular}

Figure S21. HRMS spectrum of $[\mathrm{GdL6}]^{+}$. 
Analysis Info

Sample Name

787-142 Y-Pc2pa-asym

Acquisition Date

Instrument/Seri

17/04/201911:36:34

Analysis Name X050006CYC.d

Method

maXis 255552.00086

Acquisition Parameter

Source Type

ESI

Scan Begin $\quad 50 \mathrm{~m} / \mathrm{z}$

Scan End $\quad 2500 \mathrm{~m} / \mathrm{t}$

Set Collision Call AF $1800.0 \mathrm{VPp}$

Set Nebulizer
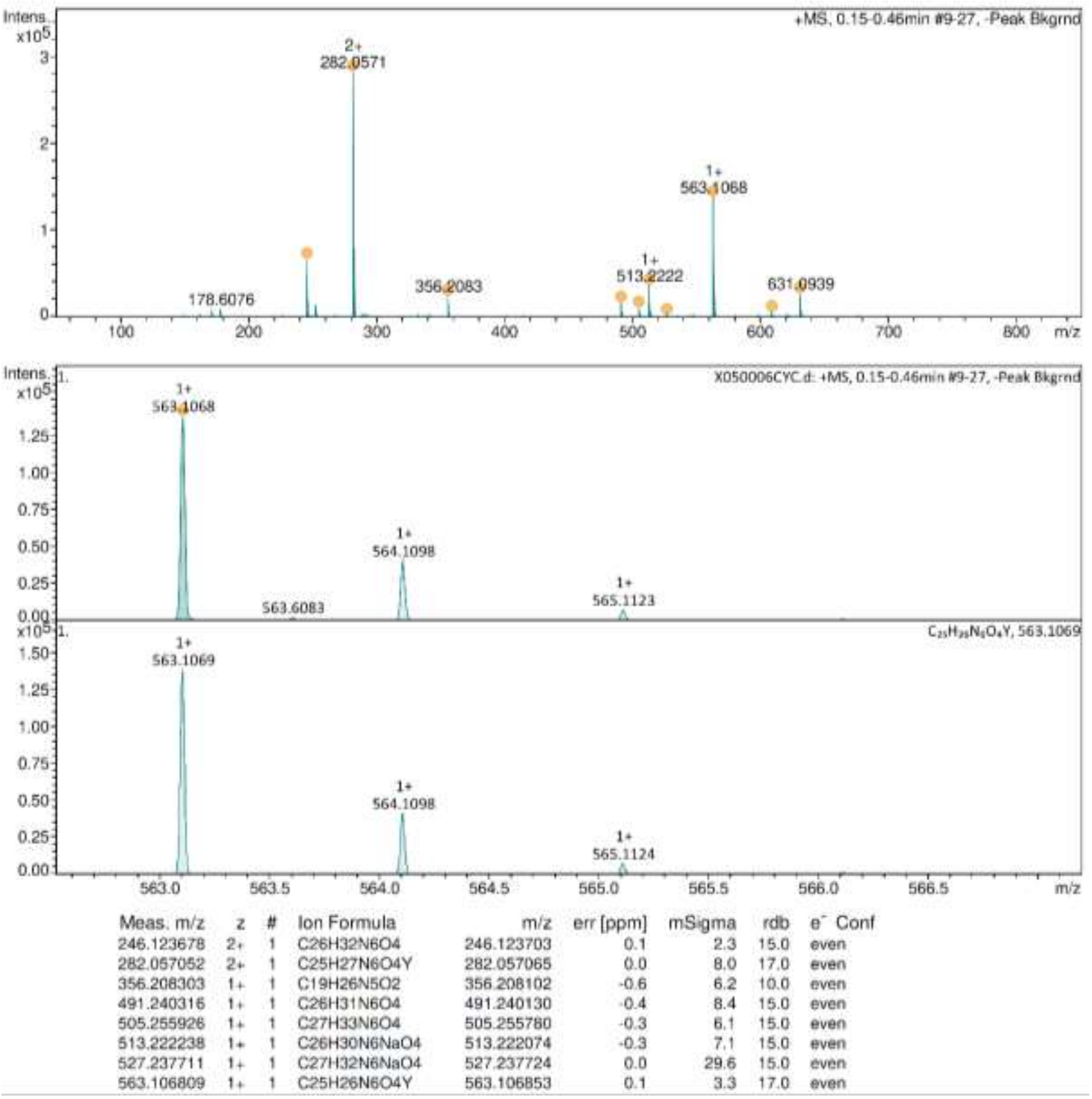

Figure S22. HRMS spectrum of [YL6 $]^{+}$. 
Analysis Info

Sample Name

Analysis Name

788-005 Eu-Pc2pa-asym

X053873CYC.d

Acquisition Parameter

Source Type

Scan Begin

Scan End

ESI

$50 \mathrm{~m} / \mathrm{z}$

Ion Polanty

Set Capilisry

Set Colision Cell RF

$4500 \mathrm{~V}$

$1800.0 \mathrm{Vpp}$
Acquisition Date

Instrument / Ser\#

Method
$11 / 12 / 201918: 26: 02$

maXis 255552.00086

Positif.m
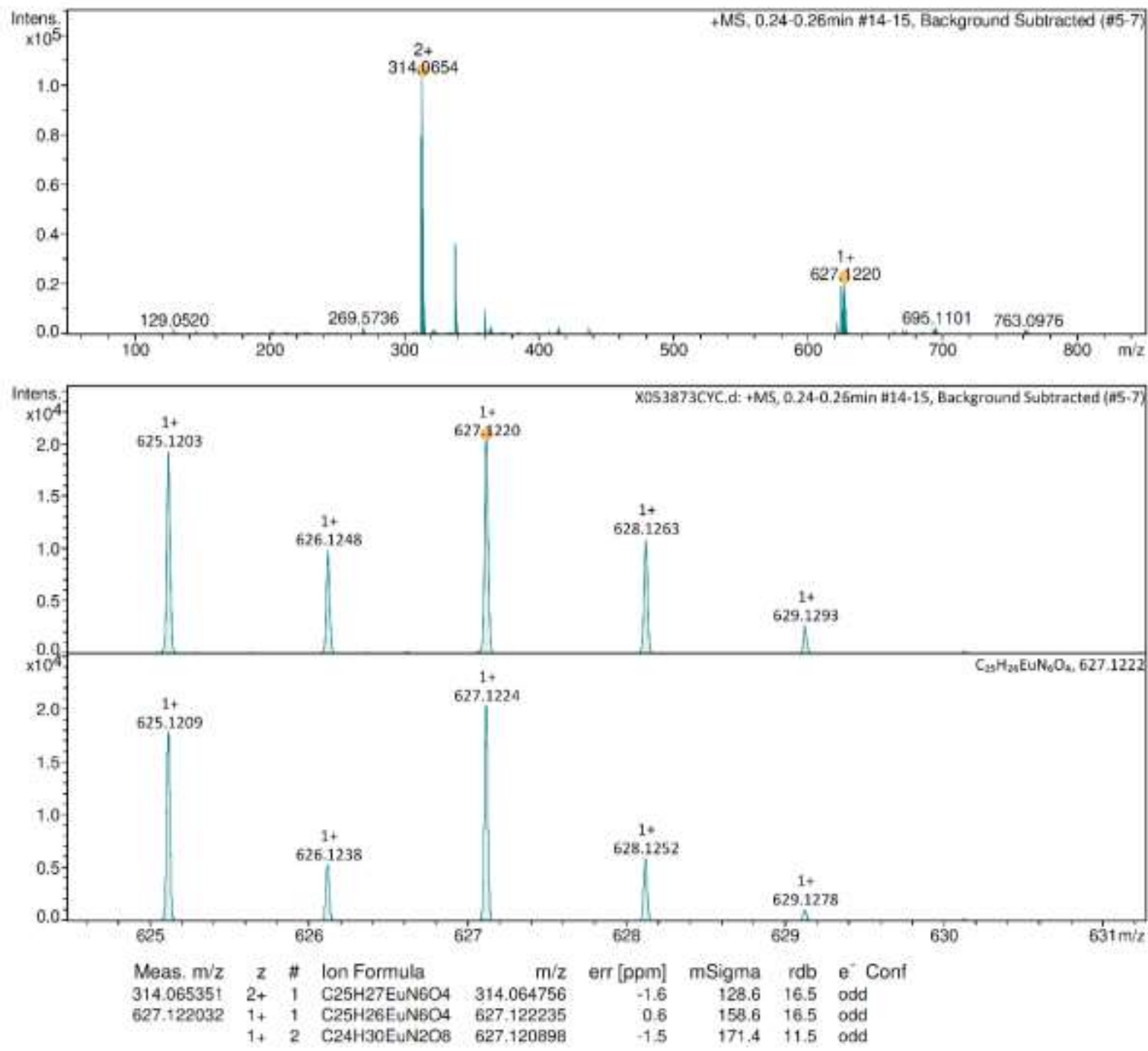

Figure S23. HRMS Spectrum of $[\mathrm{EuL6}]^{+}$. 

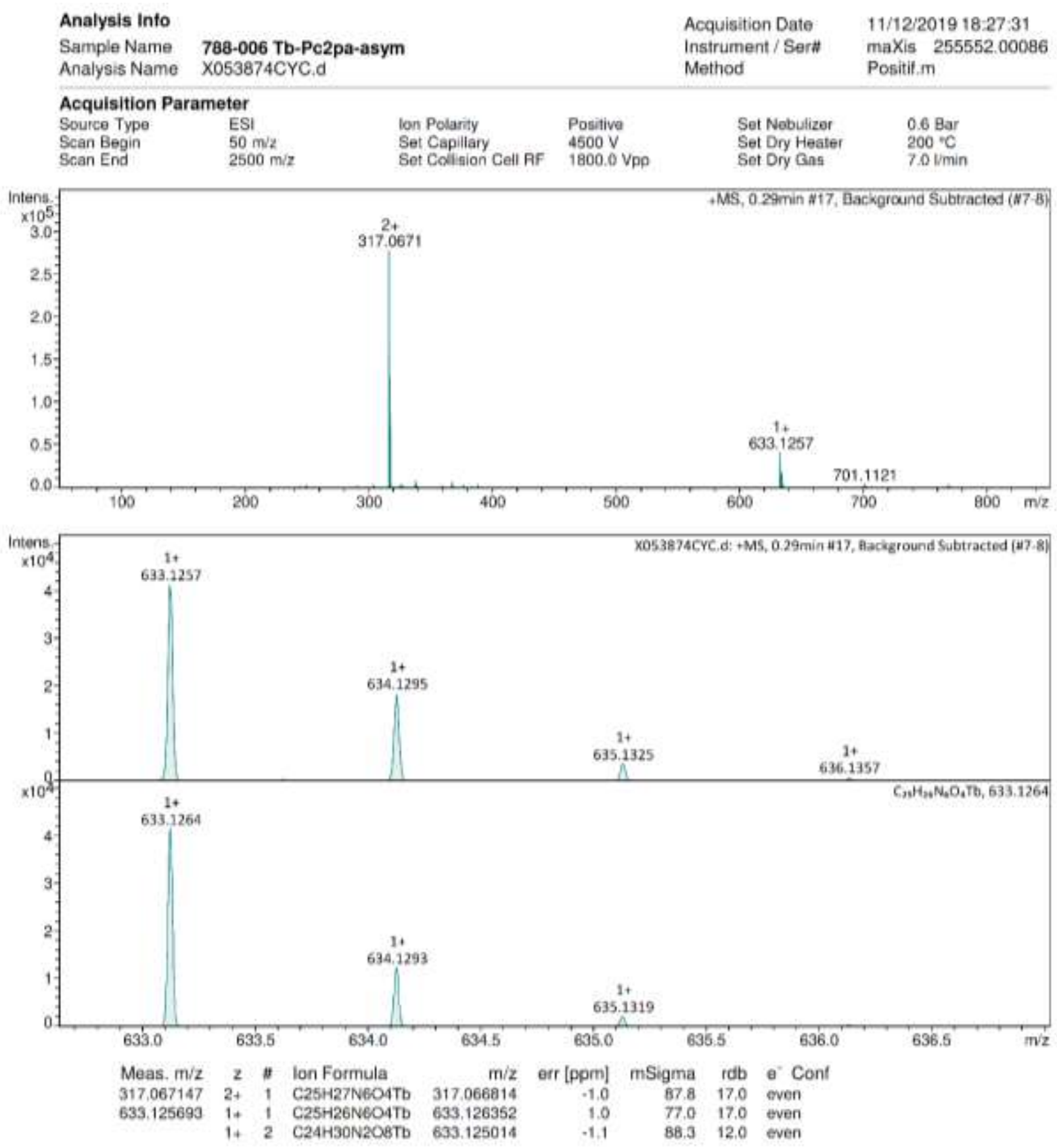

Figure S24. HRMS spectrum of [TbL6] $]^{+}$. 


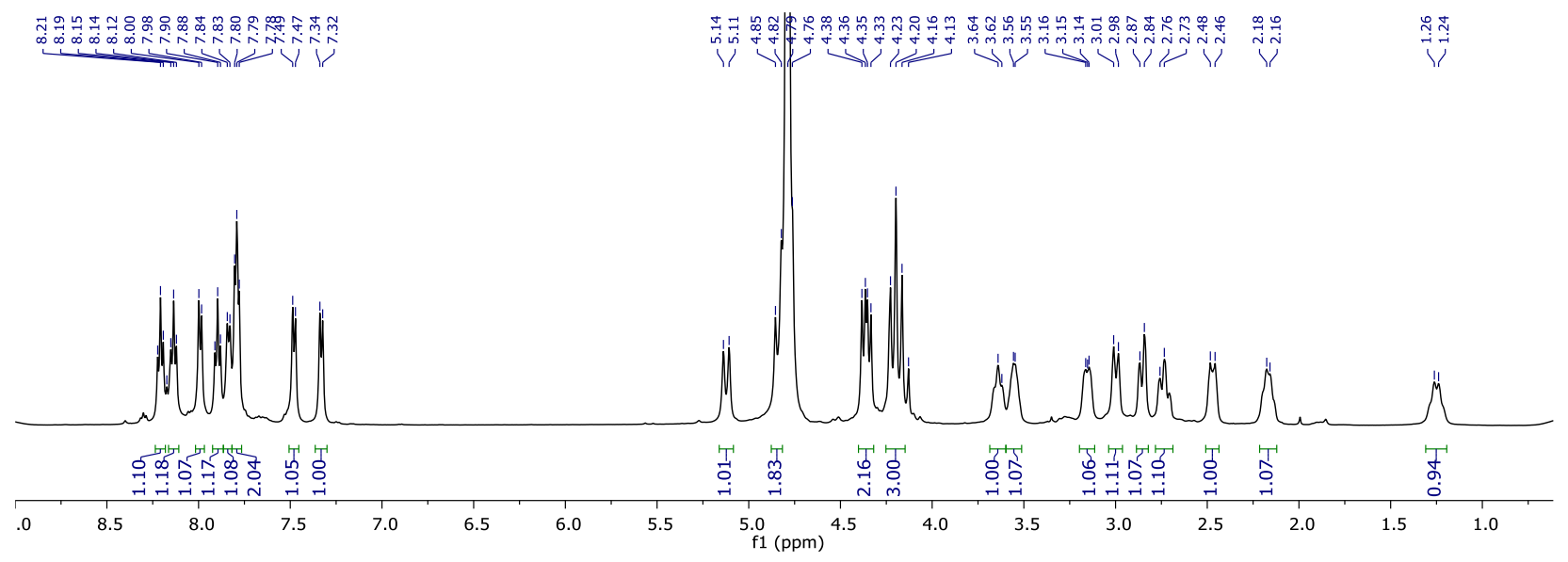

Figure $\mathrm{S} 25 .{ }^{1} \mathrm{H}$ NMR spectrum of $[\mathrm{YL5}]^{+}$in $\mathrm{D}_{2} \mathrm{O}$ at $500 \mathrm{MHz}, 298 \mathrm{~K}$.

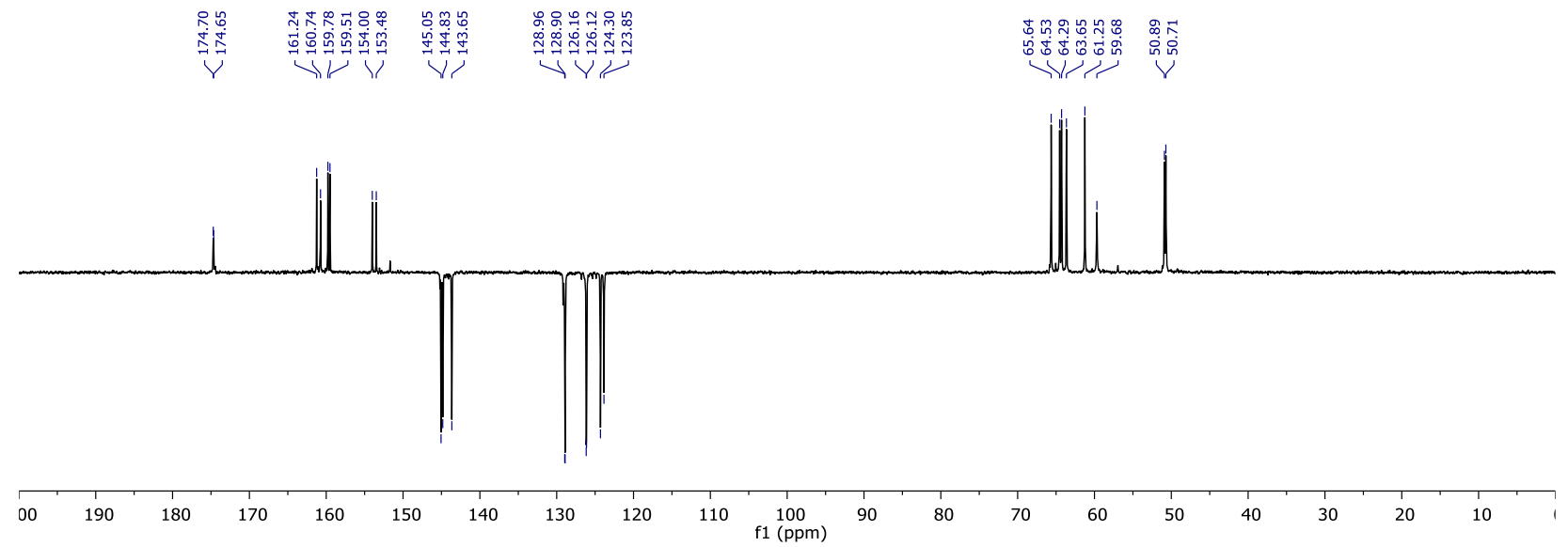

Figure S26. ${ }^{13} \mathrm{C}$ NMR spectrum of [YL5] ${ }^{+}$in $\mathrm{D}_{2} \mathrm{O}$ at $125 \mathrm{MHz}, 298 \mathrm{~K}$. 


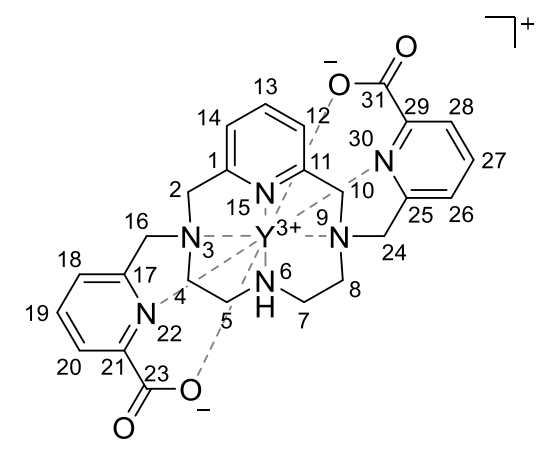

Figure S27. Atom numbering of $[\mathbf{Y} \mathbf{L 5}]^{+}$.

Table S1: NMR assignment of [YL5] ${ }^{+}$. Assignment was done using 2D NMR experiments $\left({ }^{1} \mathrm{H}-{ }^{1} \mathrm{H}\right.$

COSY, ${ }^{1} \mathrm{H}_{-}{ }^{13} \mathrm{C}$ HMQC, ${ }^{1} \mathrm{H}_{-}{ }^{13} \mathrm{C} \mathrm{HMBC}$ ) recorded in $\mathrm{D}_{2} \mathrm{O}$ at 500 and $125 \mathrm{MHz}, 298 \mathrm{~K}$.

\begin{tabular}{|c|c|c|}
\hline & $\delta^{1} \mathbf{H}(\mathbf{p p m})$ & $\delta^{13} \mathrm{C}(\mathbf{p p m})$ \\
\hline 1 & - & 159.5 \\
\hline 2 & $\begin{array}{c}4.84(\mathrm{~d}, J=16.0 \mathrm{~Hz}, 2 \mathrm{H}) \\
4.36(\mathrm{dd}, J=15.2,9.5 \mathrm{~Hz}, 2 \mathrm{H})\end{array}$ & 63.7 \\
\hline 3 & - & - \\
\hline 4 & $\begin{array}{c}3.60-3.51(\mathrm{~m}, 1 \mathrm{H}) \\
3.00(\mathrm{~d}, J=12.9 \mathrm{~Hz}, 1 \mathrm{H})\end{array}$ & 58.0 \\
\hline 5 & $\begin{array}{c}3.11(\mathrm{~m}, 1 \mathrm{H}) \\
2.21-2.12(\mathrm{~m}, 1 \mathrm{H})\end{array}$ & 50.7 \\
\hline 6 & - & - \\
\hline 7 & $\begin{array}{c}2.47(\mathrm{~d}, J=12.8 \mathrm{~Hz}, 1 \mathrm{H}) \\
1.31-1.19(\mathrm{~m}, 1 \mathrm{H})\end{array}$ & 50.9 \\
\hline 8 & $\begin{array}{c}2.85(\mathrm{~d}, J=12.2 \mathrm{~Hz}, 1 \mathrm{H}) \\
2.78-2.69(\mathrm{~m}, 1 \mathrm{H})\end{array}$ & 59.7 \\
\hline 9 & - & - \\
\hline 10 & $4.36(\mathrm{dd}, J=15.2,9.5 \mathrm{~Hz}, 2 \mathrm{H})$ & 64.3 \\
\hline 11 & - & 159.8 \\
\hline 12 & $7.48(\mathrm{~d}, J=7.5 \mathrm{~Hz}, 1 \mathrm{H})$ & 124.3 \\
\hline 13 & $7.90(\mathrm{t}, J=7.6 \mathrm{~Hz}, 1 \mathrm{H})$ & 147.3 \\
\hline 14 & $7.33(\mathrm{~d}, J=7.6 \mathrm{~Hz}, 1 \mathrm{H})$ & 123.4 \\
\hline 15 & - & - \\
\hline 16 & $\begin{array}{c}4.84(\mathrm{~d}, J=16.0 \mathrm{~Hz}, 2 \mathrm{H}) \\
4.20(\mathrm{~m}, 3 \mathrm{H})\end{array}$ & 64.5 \\
\hline 17 & - & 153.5 \\
\hline 18 & $7.82-7.77(\mathrm{~m}, 2 \mathrm{H})$ & 128.9 \\
\hline 19 & $8.14(\mathrm{t}, J=7.7 \mathrm{~Hz}, 1 \mathrm{H})$ & 144.8 \\
\hline 20 & $7.84(\mathrm{~d}, J=7.1 \mathrm{~Hz}, 1 \mathrm{H})$ & 126.1 \\
\hline 21 & - & 160.7 \\
\hline 22 & - & - \\
\hline 23 & - & 174.7 \\
\hline 24 & $\begin{array}{c}5.12(\mathrm{~d}, J=15.3 \mathrm{~Hz}, 1 \mathrm{H}) \\
4.20(\mathrm{~m}, 3 \mathrm{H})\end{array}$ & 65.6 \\
\hline 25 & - & 161.2 \\
\hline 26 & $7.82-7.77(\mathrm{~m}, 2 \mathrm{H})$ & 128.9 \\
\hline 27 & $8.21(\mathrm{t}, J=7.6 \mathrm{~Hz}, 1 \mathrm{H})$ & 145.1 \\
\hline 28 & $7.99(\mathrm{~d}, J=7.5 \mathrm{~Hz}, 1 \mathrm{H})$ & 126.1 \\
\hline 29 & - & 154.0 \\
\hline 30 & - & - \\
\hline 31 & - & 174.7 \\
\hline
\end{tabular}




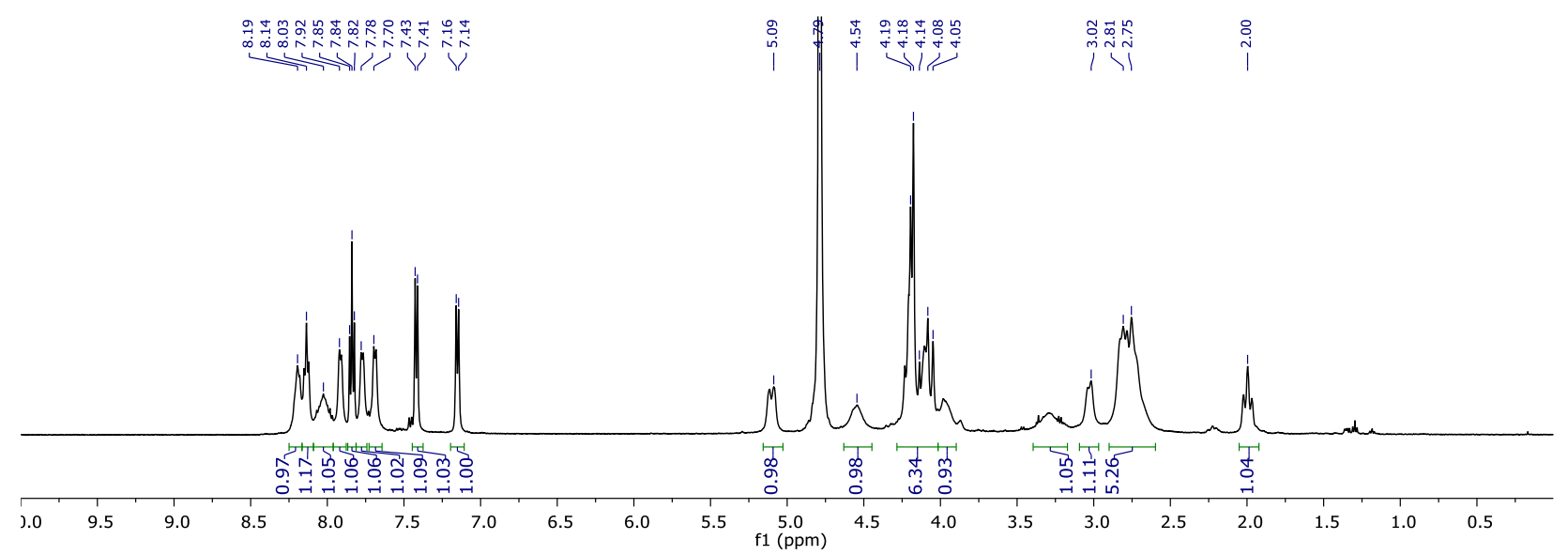

Figure S28. ${ }^{1} \mathrm{H}$ NMR spectrum of $[\mathrm{YL6}]^{+}$in $\mathrm{D}_{2} \mathrm{O}$ at $500 \mathrm{MHz}, 298 \mathrm{~K}$.

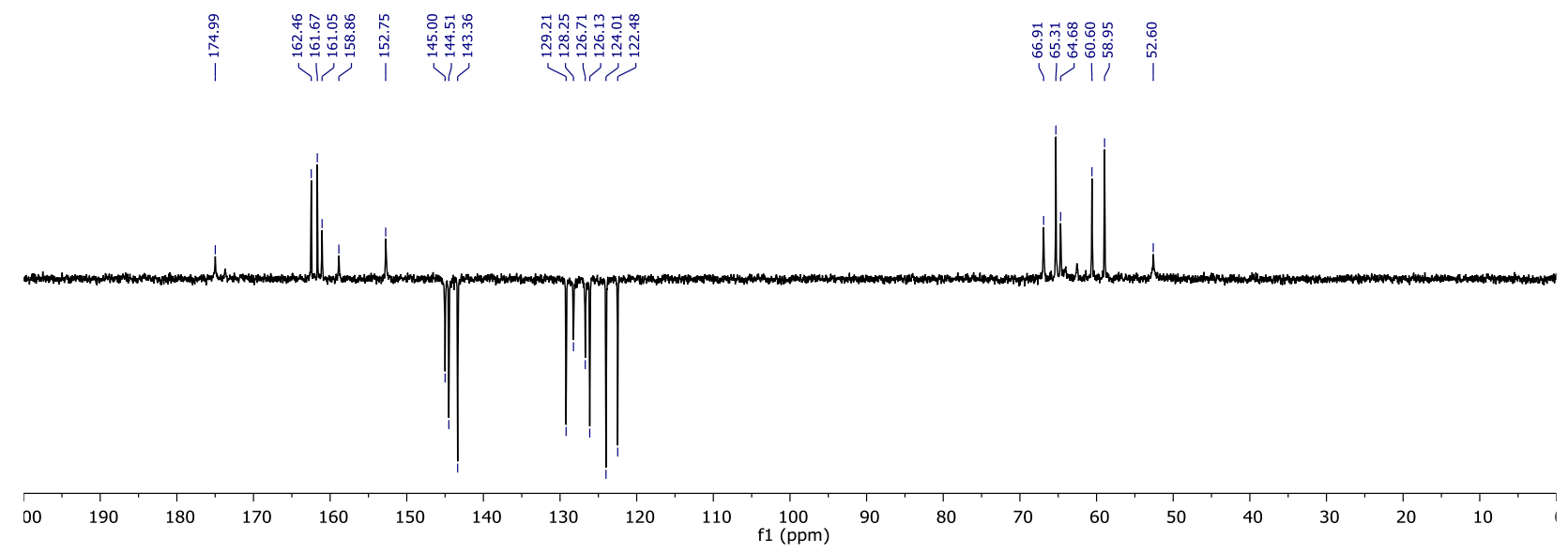

Figure S29. ${ }^{13} \mathrm{C}$ NMR Spectrum of $[\mathrm{YL6}]^{+}$in $\mathrm{D}_{2} \mathrm{O}$ at $125 \mathrm{MHz}, 298 \mathrm{~K}$. 


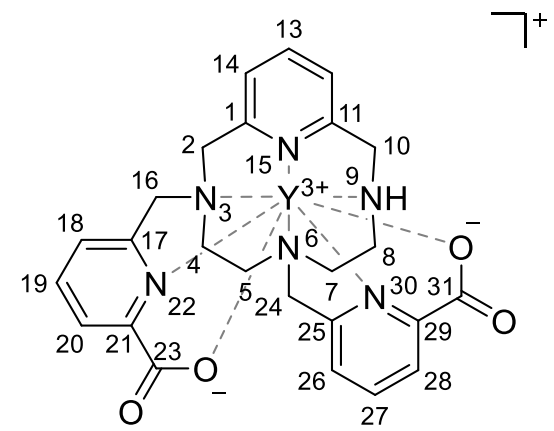

Figure S30. Atom numbering of [YL6 $]^{+}$.

Table S2. NMR assignment of [YL6] ${ }^{+}$. Assignment was done using 2D NMR experiments $\left({ }^{1} \mathrm{H}-{ }^{1} \mathrm{H}\right.$ $\mathrm{COSY},{ }^{1} \mathrm{H}^{-13} \mathrm{C} \mathrm{HMQC},{ }^{1} \mathrm{H}^{-13} \mathrm{C}$ HMBC) recorded in $\mathrm{D}_{2} \mathrm{O}$ at 500 and $125 \mathrm{MHz}, 298 \mathrm{~K}$.

\begin{tabular}{|c|c|c|}
\hline & $\delta^{1} \mathbf{H}(\mathbf{p p m})$ & $\delta^{13} \mathrm{C}(\mathrm{ppm})$ \\
\hline 1 & - & 161.7 \\
\hline 2 & $4.26-4.03(\mathrm{~m}, 6 \mathrm{H})$ & 66.9 \\
\hline 3 & - & - \\
\hline 4 & $\begin{array}{c}4.54(\mathrm{br} \mathrm{s}, 1 \mathrm{H}) \\
2.78(\mathrm{~m}, 5 \mathrm{H})\end{array}$ & 60.6 \\
\hline 5 & $\begin{array}{c}3.02(\mathrm{~d}, J=7.5 \mathrm{~Hz}, 1 \mathrm{H}) \\
2.78(\mathrm{~m}, 5 \mathrm{H})\end{array}$ & 64.7 \\
\hline 6 & - & - \\
\hline 7 & $\begin{array}{c}2.78(\mathrm{~m}, 5 \mathrm{H}) \\
2.00(\mathrm{t}, J=15 \mathrm{~Hz}, 1 \mathrm{H})\end{array}$ & 62.4 \\
\hline 8 & $2.78(\mathrm{~m}, 5 \mathrm{H})$ & 52.6 \\
\hline 9 & - & - \\
\hline 10 & $\begin{array}{c}5.09(\mathrm{~d}, J=17 \mathrm{~Hz}, 1 \mathrm{H}) \\
3.30(\mathrm{br} \mathrm{s}, 1 \mathrm{H})\end{array}$ & 59.0 \\
\hline 11 & - & 162.5 \\
\hline 12 & $7.42(\mathrm{~d}, J=7.6 \mathrm{~Hz}, 1 \mathrm{H})$ & 124.0 \\
\hline 13 & $7.84(\mathrm{t}, J=7.8 \mathrm{~Hz}, 1 \mathrm{H})$ & 143.4 \\
\hline 14 & $7.15(\mathrm{~d}, J=7.8 \mathrm{~Hz}, 1 \mathrm{H})$ & 122.5 \\
\hline 15 & - & - \\
\hline 16 & $4.26-4.03(\mathrm{~m}, 6 \mathrm{H})$ & 65.3 \\
\hline 17 & - & 152.8 \\
\hline 18 & $7.78(\mathrm{~d}, J=7.6 \mathrm{~Hz}, 1 \mathrm{H})$ & 128.3 \\
\hline 19 & $8.19(\mathrm{~m}, 1 \mathrm{H})$ & 145.0 \\
\hline 20 & $8.03(\mathrm{~m}, 1 \mathrm{H})$ & 126.7 \\
\hline 21 & - & 161.1 \\
\hline 22 & - & - \\
\hline 23 & - & 175.0 \\
\hline 24 & $4.26-4.03(\mathrm{~m}, 6 \mathrm{H})$ & 65.3 \\
\hline 25 & - & 152.8 \\
\hline 26 & $7.70(\mathrm{~d}, J=7.8 \mathrm{~Hz}, 1 \mathrm{H})$ & 129.2 \\
\hline 27 & $8.14(\mathrm{~m}, 1 \mathrm{H})$ & 144.5 \\
\hline 28 & $7.92(\mathrm{~d}, J=7.6 \mathrm{~Hz}, 1 \mathrm{H})$ & 126.1 \\
\hline 29 & - & 158.9 \\
\hline 30 & - & - \\
\hline 31 & - & 175.0 \\
\hline
\end{tabular}




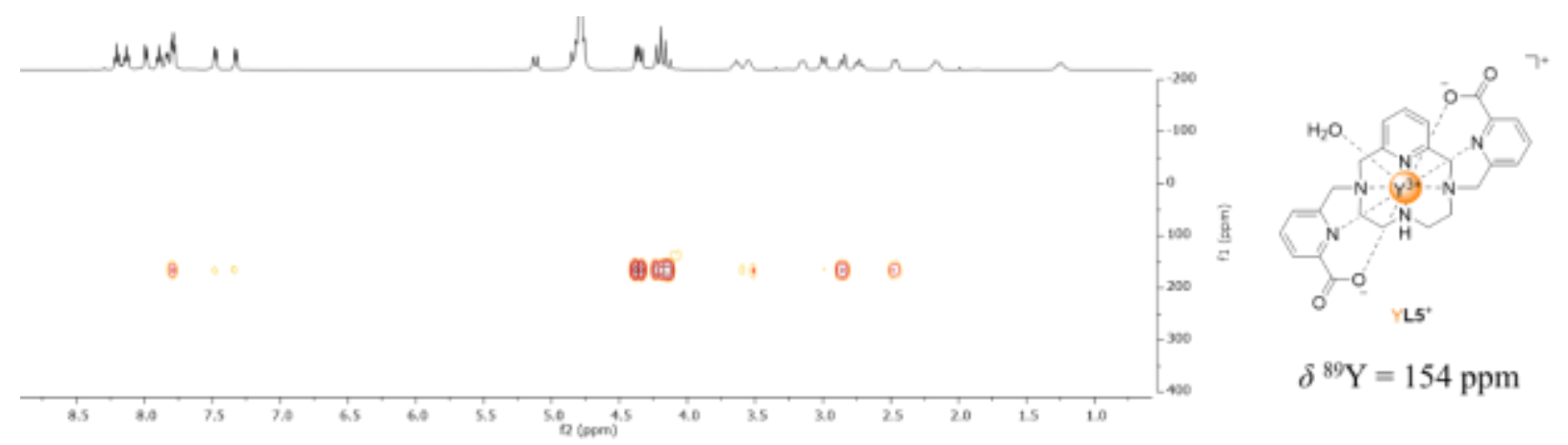

Figure S31. ${ }^{1} \mathrm{H}^{89}{ }^{\mathrm{Y}} \mathrm{HMQC}$ NMR spectrum of $[\mathrm{YL5}]^{+}$in $\mathrm{D}_{2} \mathrm{O}$ at $500 \mathrm{MHz}, 298 \mathrm{~K}$.

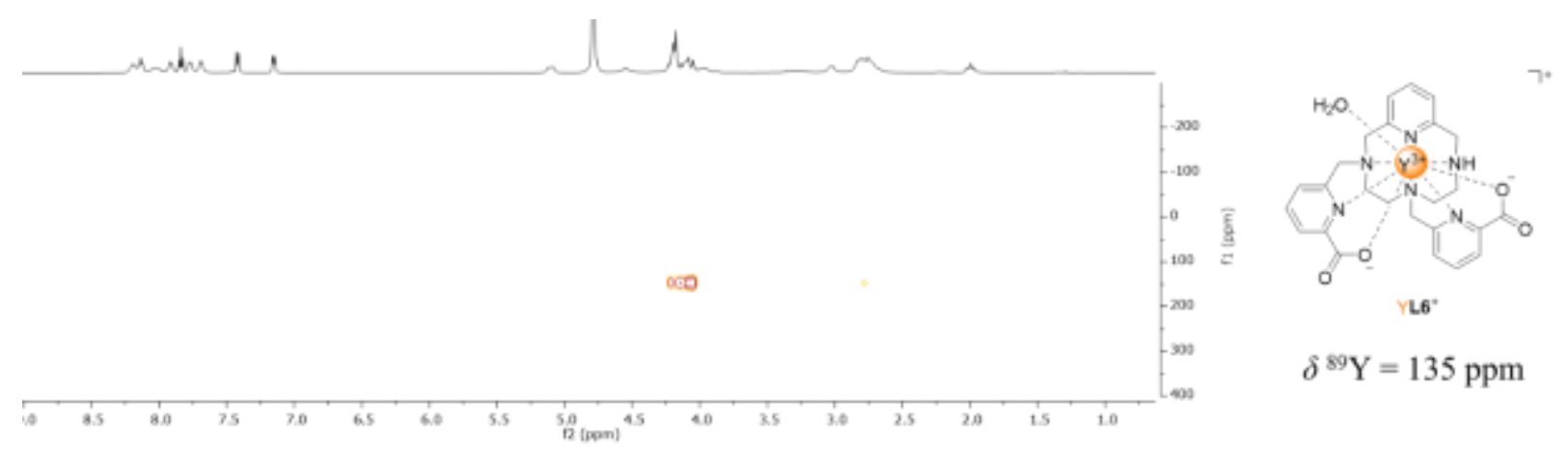

Figure $\mathrm{S} 32{ }^{1} \mathrm{H}^{89}{ }^{\mathrm{Y}} \mathrm{HMQC}$ NMR spectrum of $[\mathbf{Y L 6}]^{+}$in $\mathrm{D}_{2} \mathrm{O}$ at $500 \mathrm{MHz}, 298 \mathrm{~K}$. 


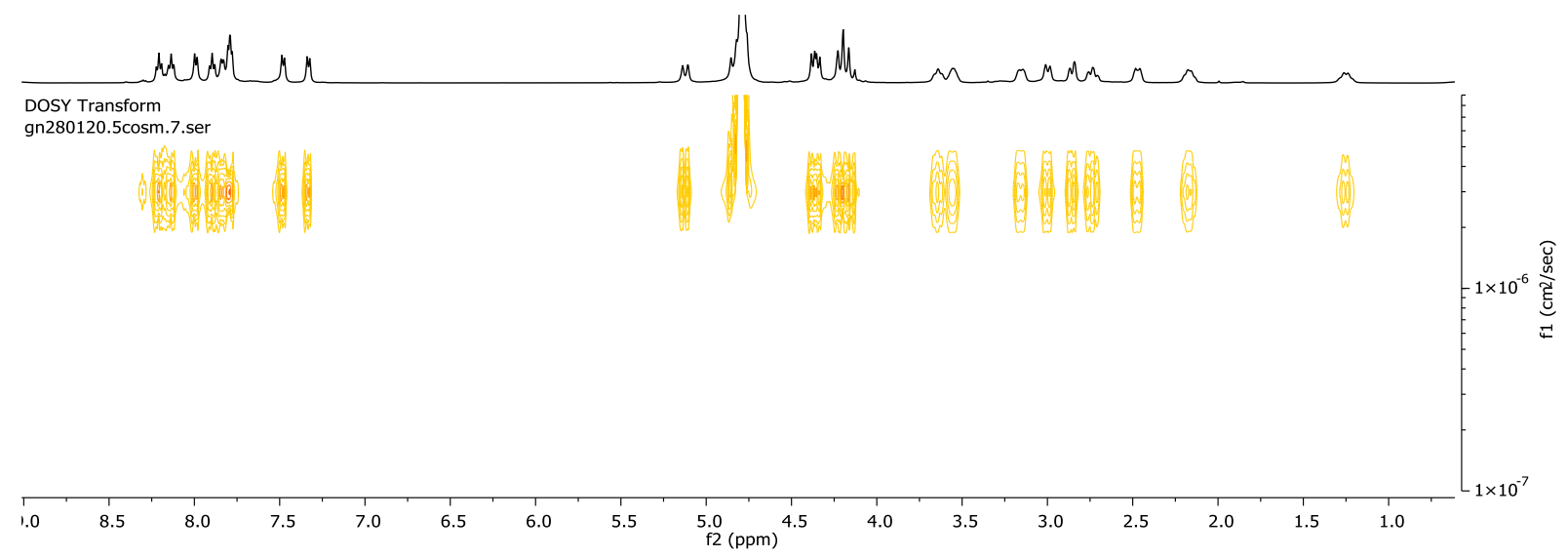

Figure S33. DOSY NMR Spectrum of $\left[\mathrm{YL5}^{+}\right.$in $\mathrm{D}_{2} \mathrm{O}$ at $500 \mathrm{MHz}, 298 \mathrm{~K}$.

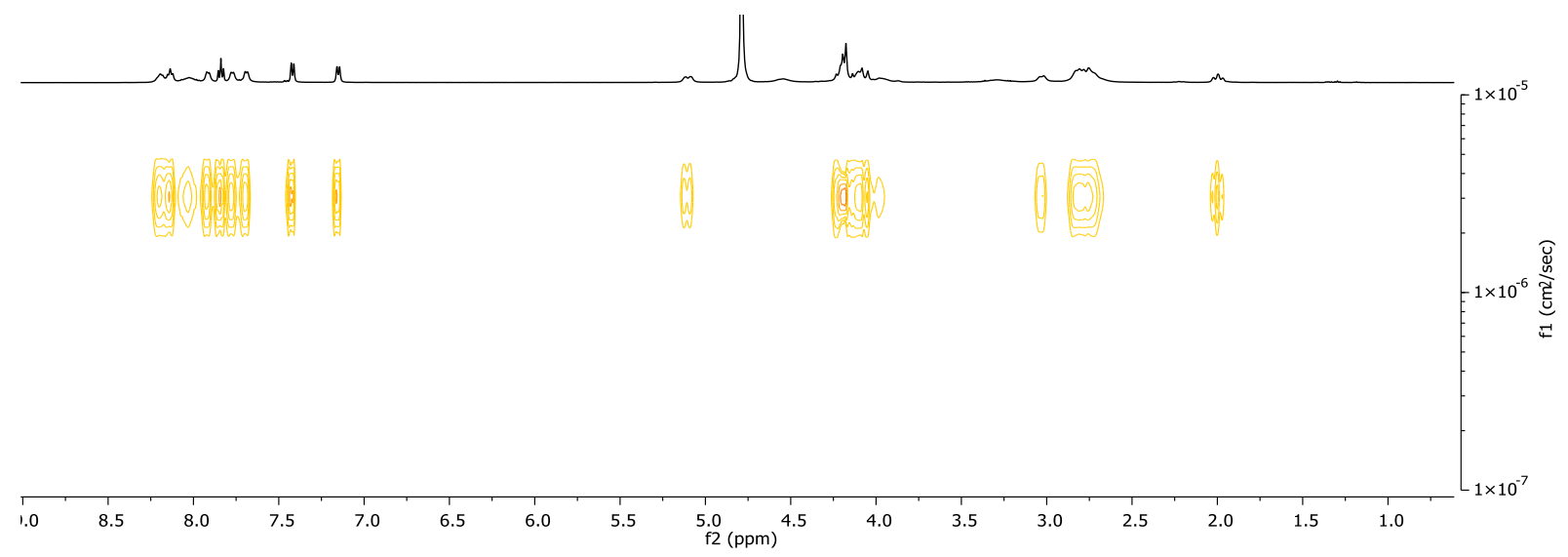

Figure S34. DOSY NMR Spectrum of [YL6] $]^{+}$in $\mathrm{D}_{2} \mathrm{O}$ at $500 \mathrm{MHz}, 298 \mathrm{~K}$. 

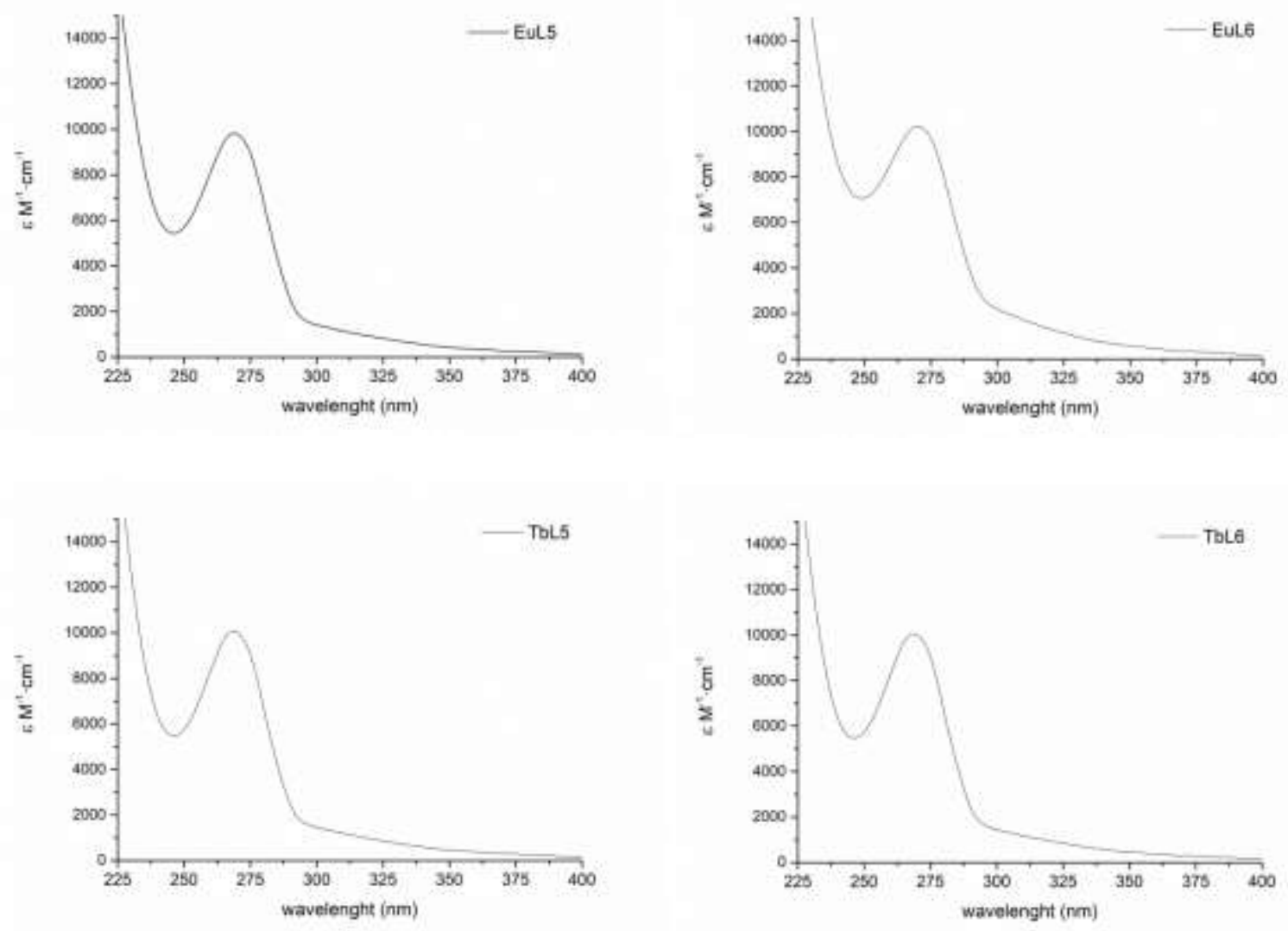

Figure S35. Absorption spectra of the $[\mathrm{LnL5}]^{+}$and $[\mathrm{LnL6}]^{+}$complexes $(\mathrm{Ln}=\mathrm{Eu}, \mathrm{Tb})\left(1 \times 10^{-5} \mathrm{M}\right.$, Tris/ $\left.\mathrm{HCl} 0.1 \mathrm{M}, \mathrm{pH} 6.8,25^{\circ} \mathrm{C}\right)$. 

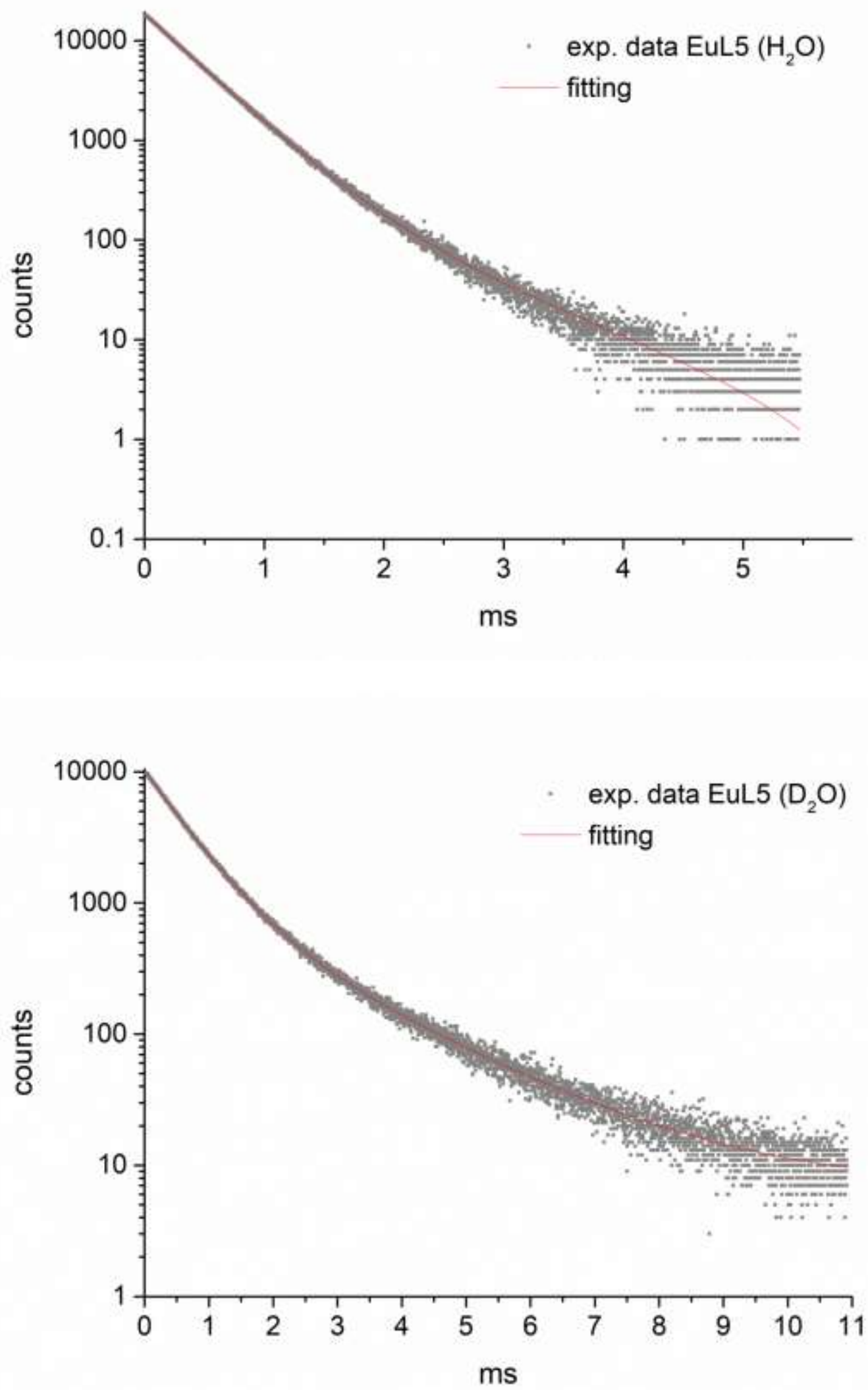

Figure S36. Emission decay profiles recorded in $\mathrm{H}_{2} \mathrm{O}$ (top) and $\mathrm{D}_{2} \mathrm{O}$ (bottom) solutions of the [EuL5] ${ }^{+}$ complex $\left(1 \times 10^{-5} \mathrm{M}, \lambda_{\mathrm{exc}}=272 \mathrm{~nm}, \lambda_{\mathrm{em}}=613 \mathrm{~nm}\right.$, Tris $\left./ \mathrm{HCl} 0.1 \mathrm{M}, \mathrm{pH} 6.8,25^{\circ} \mathrm{C}\right)$. The red lines correspond to the fit of the data according to a double exponential decay function. 

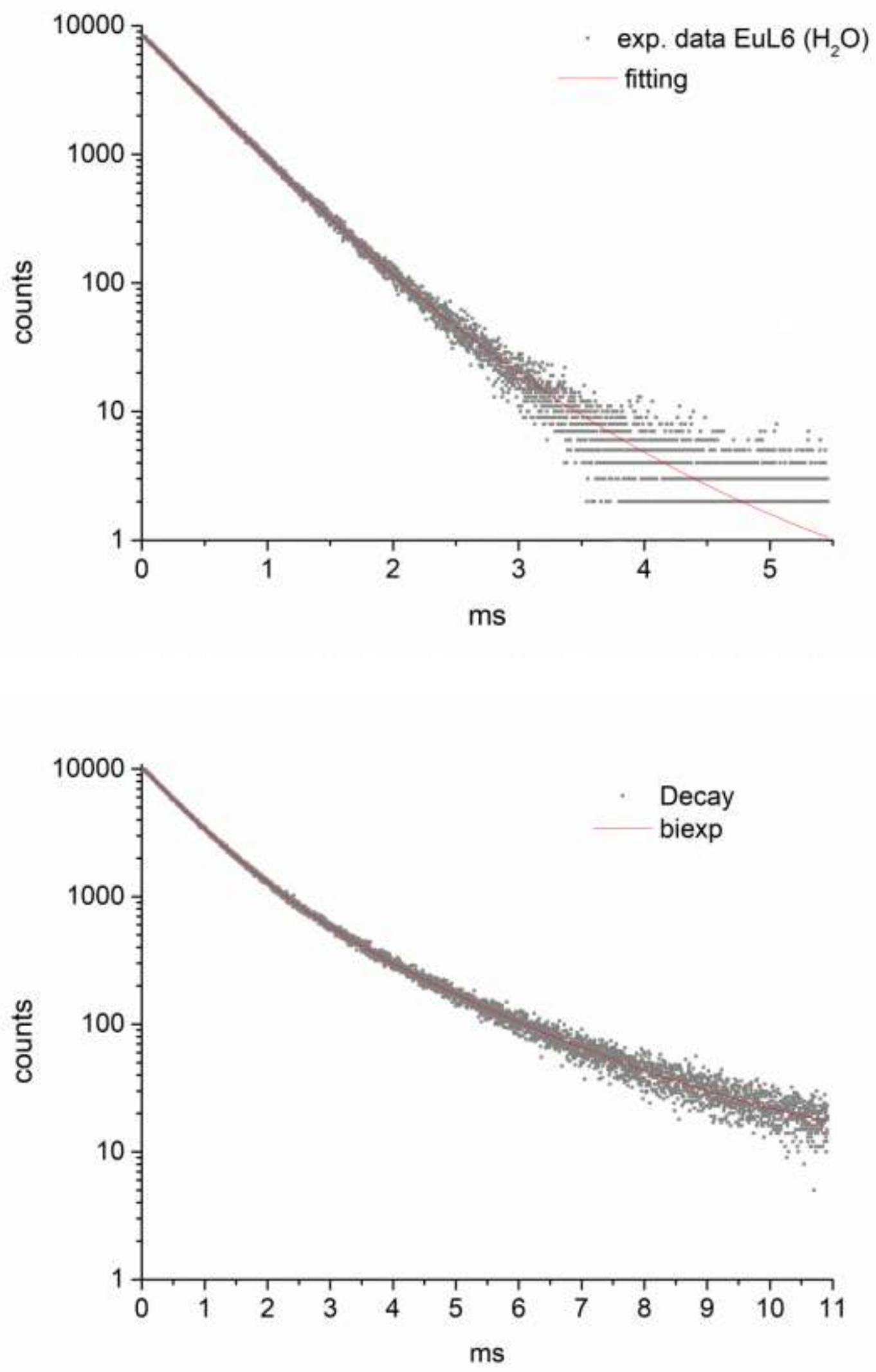

Figure S37. Emission decay profiles recorded in $\mathrm{H}_{2} \mathrm{O}$ (top) and $\mathrm{D}_{2} \mathrm{O}$ (bottom) solutions of the [EuL6] ${ }^{+}$ complex $\left(1 \times 10^{-5} \mathrm{M}, \lambda_{\mathrm{exc}}=272 \mathrm{~nm}, \lambda_{\mathrm{em}}=613 \mathrm{~nm}\right.$, Tris $\left./ \mathrm{HCl} 0.1 \mathrm{M}, \mathrm{pH} 6.8,25^{\circ} \mathrm{C}\right)$. The red lines correspond to the fit of the data according to a double exponential decay function. 

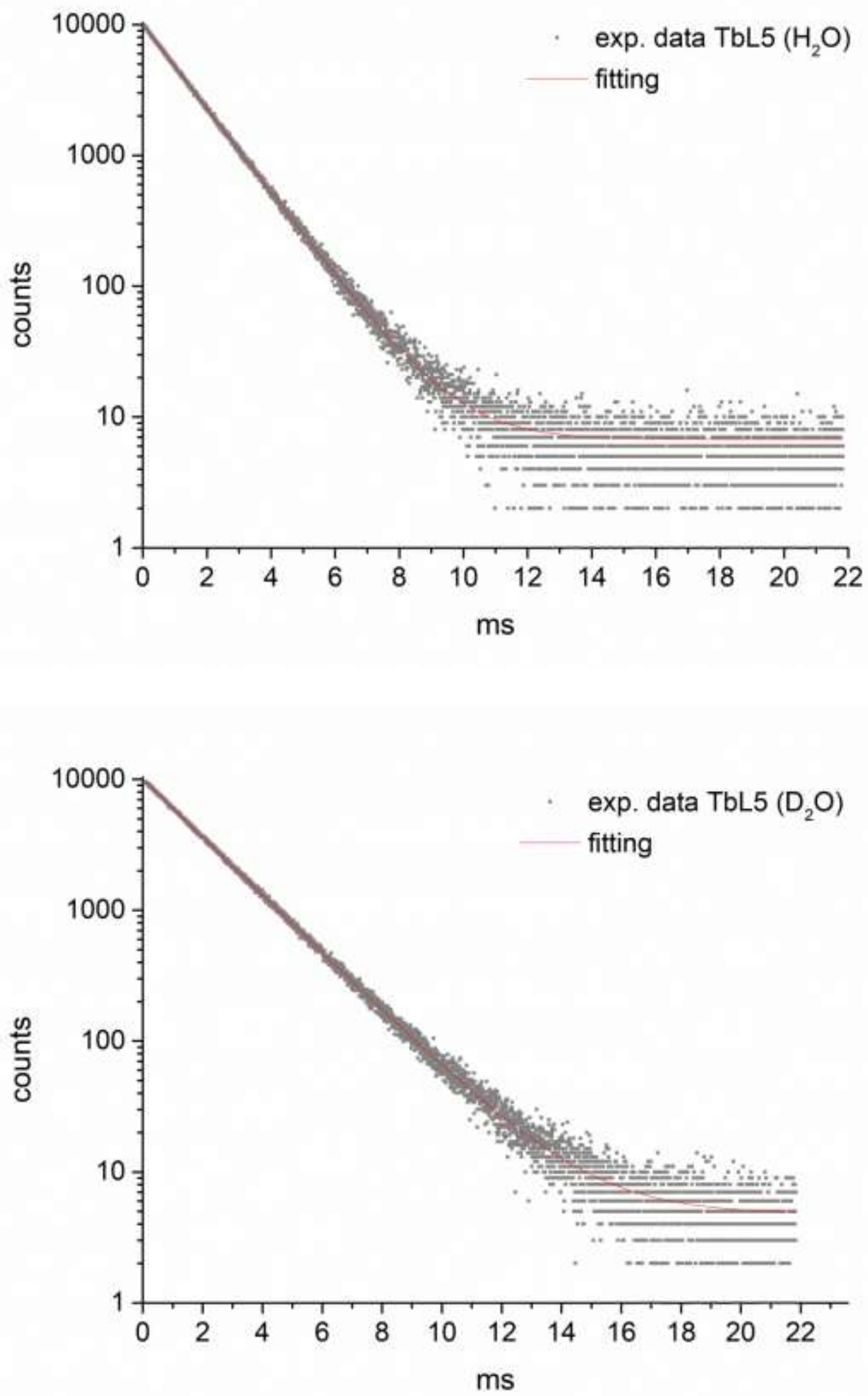

Figure S38. Emission decay profiles recorded in $\mathrm{H}_{2} \mathrm{O}$ (top) and $\mathrm{D}_{2} \mathrm{O}$ (bottom) solutions of the $[\mathbf{T b} \mathbf{L} \mathbf{5}]^{+}$ complex $\left(1 \times 10^{-5} \mathrm{M}, \lambda_{\mathrm{exc}}=272 \mathrm{~nm}, \lambda_{\mathrm{em}}=545 \mathrm{~nm}\right.$, Tris $\left./ \mathrm{HCl} 0.1 \mathrm{M}, \mathrm{pH} 6.8,25^{\circ} \mathrm{C}\right)$. The red lines correspond to the fit of the data according to a single exponential decay function. 

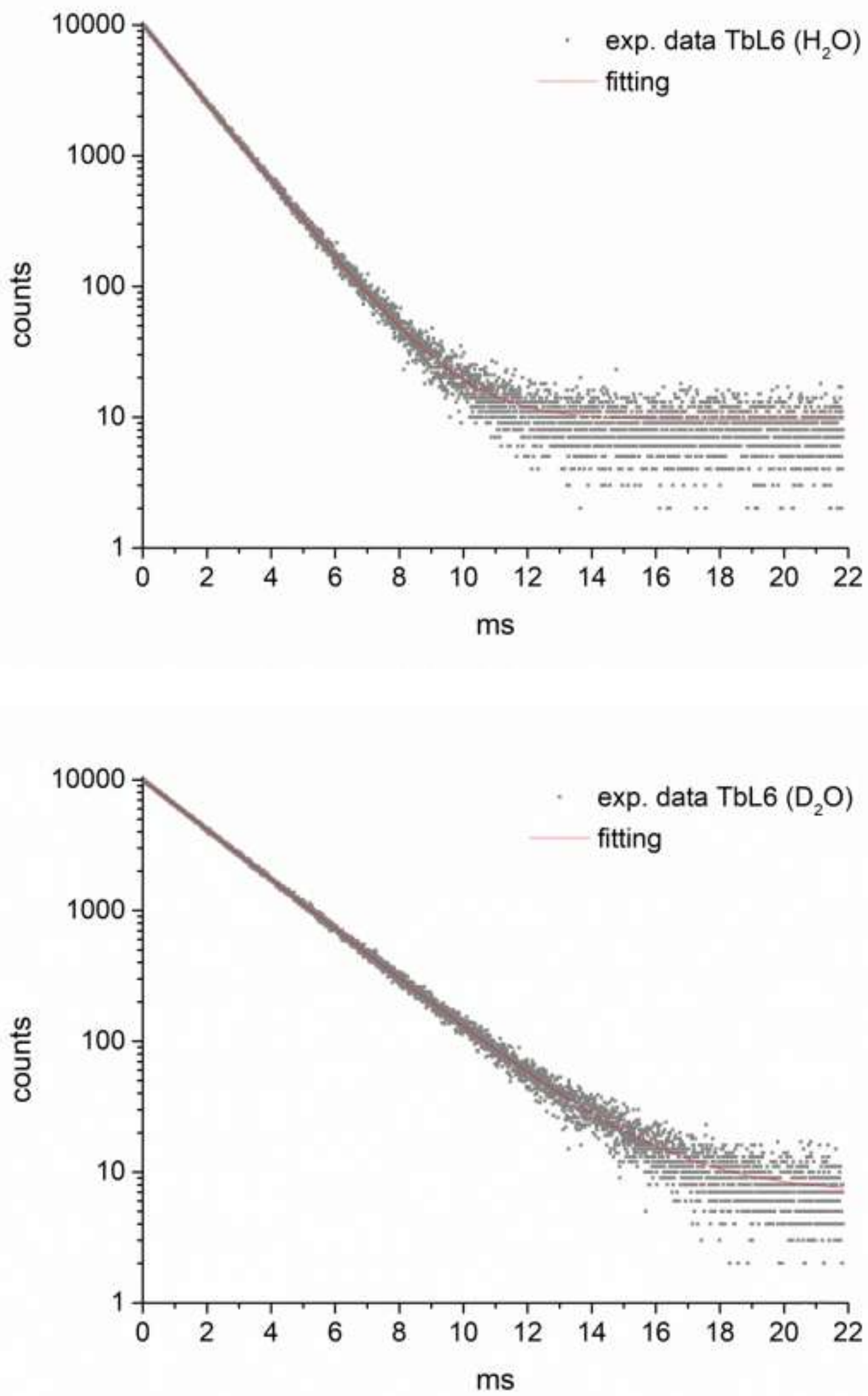

Figure S39. Emission decay profiles recorded in $\mathrm{H}_{2} \mathrm{O}$ (top) and $\mathrm{D}_{2} \mathrm{O}$ (bottom) solutions of the [TbL6] ${ }^{+}$ complex $\left(1 \times 10^{-5} \mathrm{M}, \lambda_{\mathrm{exc}}=272 \mathrm{~nm}, \lambda_{\mathrm{em}}=545 \mathrm{~nm}\right.$, Tris $\left./ \mathrm{HCl} 0.1 \mathrm{M}, \mathrm{pH} 6.8,25^{\circ} \mathrm{C}\right)$. The red lines correspond to the fit of the data according to a single exponential decay function. 


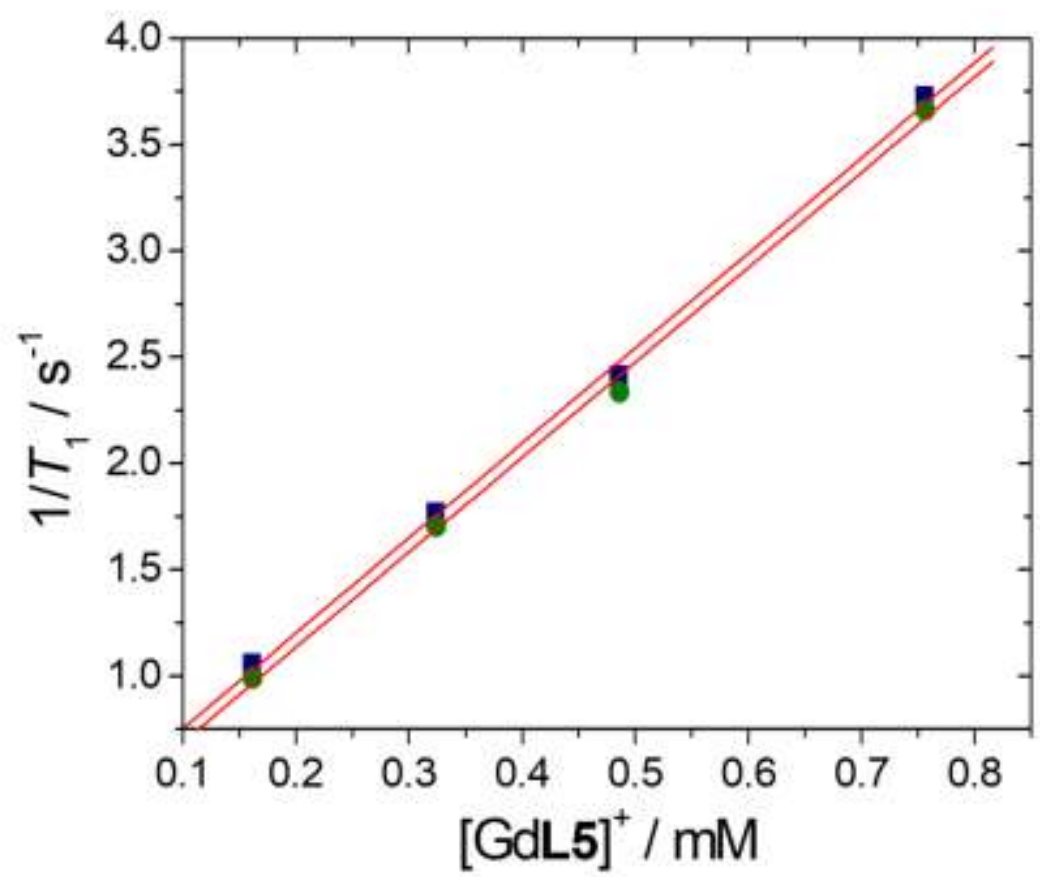

Figure S40. Longitudinal relaxation rate of water proton nuclei measured from aqueous solutions of the $[\mathrm{GdL5}]^{+}$complex (pH 7.4, 0.1 M HEPES buffer, $298 \mathrm{~K}$ ) at 20 (squares) and 60 (circles) MHz. The lines correspond to the linear fits of the data according to $1 / T_{1}=1 / T_{1}{ }^{\text {dia }}+r_{1 \mathrm{p}}[\mathrm{Gd}(\mathrm{III})]$.

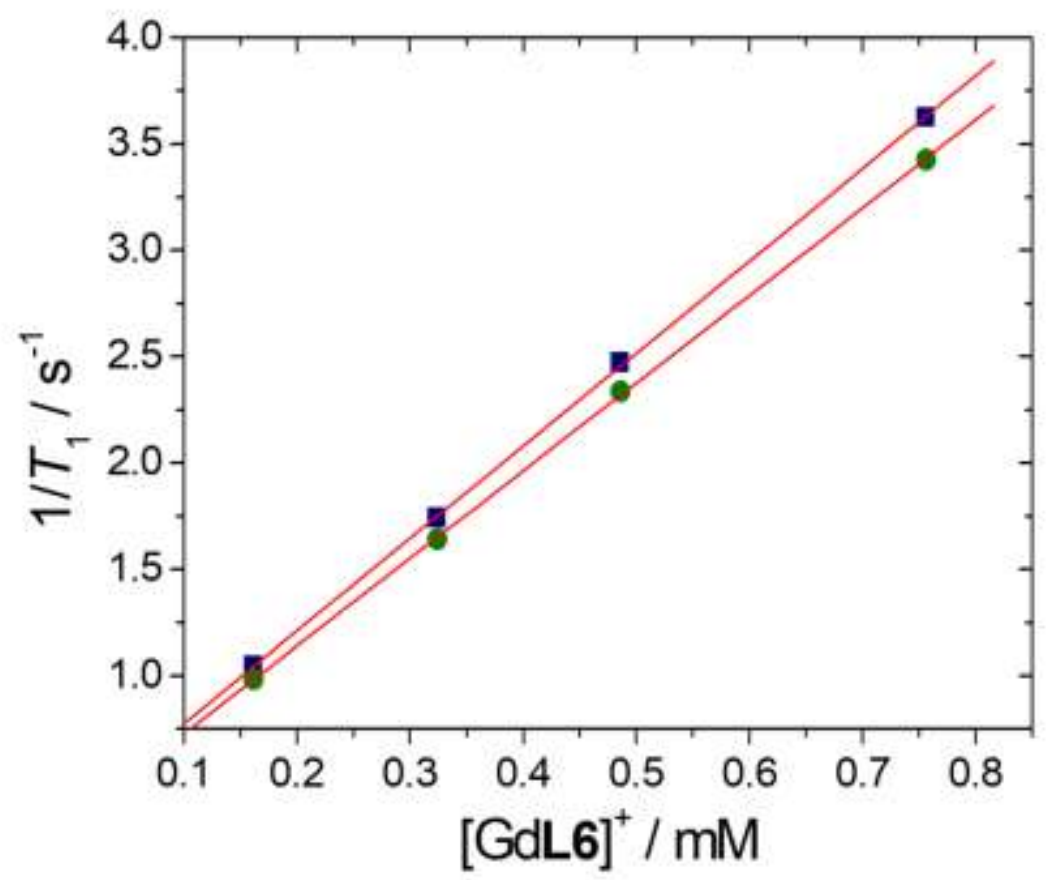

Figure S41. Longitudinal relaxation rate of water proton nuclei measured from aqueous solutions of the $[\mathrm{GdL6}]^{+}$complex (pH 7.4, 0.1 M HEPES buffer, $298 \mathrm{~K}$ ) at 20 (squares) and 60 (circles) MHz. The lines correspond to the linear fits of the data according to $1 / T_{1}=1 / T_{1}{ }^{\mathrm{dia}}+r_{1 \mathrm{p}}[\mathrm{Gd}(\mathrm{III})]$. 


\begin{tabular}{lcc}
\cline { 2 - 3 } & [GdL5 $^{+}$ & [GdL6] $^{+}$ \\
\hline Gd1-N1 & 2.527 & 2.580 \\
Gd1-N2 & 2.609 & 2.662 \\
Gd1-N3 & 2.599 & 2.590 \\
Gd1-N4 & 2.561 & 2.612 \\
Gd1-N5 & 2.629 & 2.654 \\
Gd1-N6 & 2.520 & 2.528 \\
Gd1-O1 & 2.431 & 2.427 \\
Gd1-O2 & 2.398 & 2.402 \\
Gd1-O1w & 2.483 & 2.452 \\
\hline
\end{tabular}
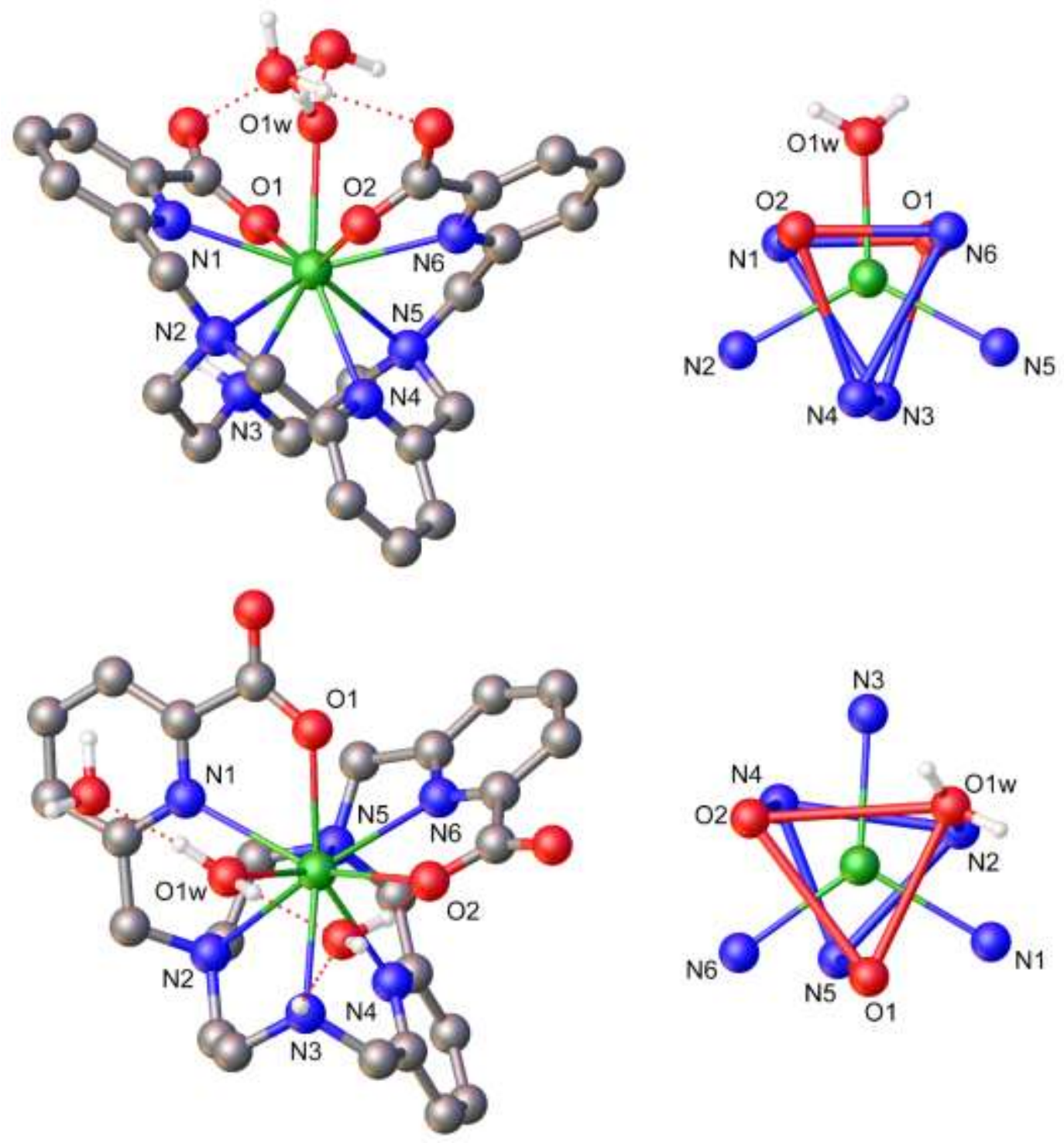

Figure S42. Structures of the $\left[\operatorname{Gd} \mathbf{L 5}\left(\mathrm{H}_{2} \mathrm{O}\right)\right]^{+} \cdot 2 \mathrm{H}_{2} \mathrm{O}$ (top) and $\left[\mathrm{Gd} \mathbf{L 6}\left(\mathrm{H}_{2} \mathrm{O}\right)\right]^{+} \cdot 2 \mathrm{H}_{2} \mathrm{O}$ (bottom) systems obtained with DFT calculations and bond distances of the metal coordination environment. 
Table S3. Cartesian coordinates $(\AA)$ of the $\left[\operatorname{GdL5}\left(\mathrm{H}_{2} \mathrm{O}\right)\right]^{+} \cdot 2 \mathrm{H}_{2} \mathrm{O}$ system optimized with DFT calculations.

C,0,1.4903049934,-0.2082102976,-3.0628690202

$\mathrm{H}, 0,2.2712535605,-0.0828659236,-3.8308495543$

$\mathrm{H}, 0,0.5705494912,0.2709098726,-3.4194538755$

C, $0,1.2367033786,-1.6957527451,-2.8344809251$

$\mathrm{H}, 0,0.9929544036,-2.1711020825,-3.7943102885$

$\mathrm{H}, 0,2.1487381486,-2.182602553,-2.4659646916$

C, $0,0.2432950871,-3.2472198124,-1.2049487328$

$\mathrm{H}, 0,1.2840201385,-3.4250603542,-0.9130990529$

H, $,-0.0250623057,-4.0442311319,-1.9143105909$

C, $0,-0.6991776358,-3.3497774501,-0.005206984$

$\mathrm{H}, 0,-1.7282255687,-3.3126113478,-0.3801211201$

$\mathrm{H}, 0,-0.5674914184,-4.329188987,0.4819437511$

C, $0,0.5649478489,-2.5183716873,1.9371376718$

$\mathrm{H}, 0,0.4907067003,-3.5234163816,2.3807845155$

$\mathrm{H}, 0,0.5019960553,-1.7727483564,2.7391269484$

C, $0,1.898196328,-2.3586862507,1.2412530644$

C, $0,2.9458543347,-3.2377270178,1.4595553012$

$\mathrm{H}, 0,2.8314352641,-4.0562834524,2.1656296934$

C,0,4.11767245,-3.0699926476,0.731399906

$\mathrm{H}, 0,4.9524650211,-3.7539159953,0.8689242018$

C, $0,4.2002588229,-2.0432075253,-0.1935827627$

$\mathrm{H}, 0,5.0895078643,-1.9027147128,-0.8034237211$

C, $0,3.1126981583,-1.1864765798,-0.3411784685$

C, $0,3.1903100851,-0.0204907472,-1.3042223289$

$\mathrm{H}, 0,3.8470416339,-0.2827983902,-2.1483733211$

$\mathrm{H}, 0,3.6863173004,0.7964806089,-0.7643993809$

C, $0,1.9678235883,1.9361421675,-1.9932428623$

$\mathrm{H}, 0,1.0463422445,2.2672710081,-2.4933850032$

$\mathrm{H}, 0,2.8200325516,2.2190445099,-2.6300701981$

C, $0,2.058013078,2.6141530518,-0.6360623771$

C, $0,2.7141322641,3.8166275438,-0.4010254168$

$\mathrm{H}, 0,3.2387035064,4.32290298,-1.207753479$

C, $0,2.6815378434,4.3481847904,0.8827945838$

$\mathrm{H}, 0,3.1882148754,5.2878277729,1.092923963$

C,0,1.9989306544,3.6805509922,1.8949372069

$\mathrm{H}, 0,1.9323357898,4.0683048953,2.907629964$

C, $0,1.3861629587,2.4813121367,1.5789350353$

C, $0,0.5554506186,1.6704977998,2.5775109211$

C, $0,-1.8150345657,-2.1191843192,1.7598740336$

$\mathrm{H}, 0,-1.6495762985,-1.3814469779,2.5586701837$

$\mathrm{H}, 0,-2.1233968085,-3.0709541749,2.2204947525$

$\mathrm{N}, 0,1.8871682962,0.4700994338,-1.8061110771$

$\mathrm{N}, 0,0.1670274562,-1.9159093833,-1.8359093934$

$\mathrm{N}, 0,-0.5510309301,-2.2650086432,1.0050240268$

$\mathrm{N}, 0,1.9988665084,-1.3390472024,0.3744172299$

$\mathrm{N}, 0,1.4326911428,1.9748824697,0.3493904039$

$\mathrm{O}, 0,0.2190172225,0.5030158772,2.1899353676$

$\mathrm{O}, 0,0.2295337852,2.2041620723,3.6389987619$

Gd,0,-0.1000287584,0.0358639052,-0.1405146633

C, $0,-2.9052719269,-1.5883120318,0.8498420375$

C, $0,-4.2619642947,-1.8330428046,1.030197584$

C, $0,-5.1627960661,-1.2460690274,0.1509104664$ 
$\mathrm{H}, 0,-4.6011679617,-2.4695699128,1.8438350711$

C, $0,-3.332798442,-0.2485792863,-0.9909295437$

C, $0,-4.6986626129,-0.4317274069,-0.8779964975$

$\mathrm{H}, 0,-6.2299544528,-1.4215770665,0.2699444208$

$\mathrm{H}, 0,-5.36547822,0.0616566569,-1.579330277$

$\mathrm{N}, 0,-2.4760504241,-0.8239227372,-0.1501442594$

C, $0,-2.6976486539,0.6764374034,-2.0330661622$

$\mathrm{O}, 0,-1.4248680628,0.6536485012,-2.0833263539$

$\mathrm{O}, 0,-3.4466997226,1.3976132438,-2.6967699531$

$\mathrm{H}, 0,-0.7340119082,-1.8204555569,-2.3067968618$

$\mathrm{O}, 0,-1.5742712217,1.922419742,0.5168712638$

$\mathrm{H}, 0,-2.0340907424,1.8861411585,1.3830882647$

$\mathrm{H}, 0,-1.9386228319,2.6141028453,-0.0741087105$

$\mathrm{O}, 0,-2.3487762806,3.6578152678,-1.4691914686$

O,0,-2.4497399072,1.4099409259,3.0410724859

$\mathrm{H}, 0,-2.7299234204,3.0386413293,-2.1179874325$

$\mathrm{H}, 0,-1.559818985,4.0272320327,-1.8772461461$

$\mathrm{H}, 0,-3.1018199198,1.9272923609,3.5229928417$

$\mathrm{H}, 0,-1.5975391058,1.549661605,3.4923320322$

$\mathrm{E}(\mathrm{RM} 11)=-1862.7229162$ Hartree

Zero-point correction $=0.572544$

Thermal correction to Energy $=0.609458$

Thermal correction to Enthalpy $=0.610402$

Thermal correction to Gibbs Free Energy $=0.506469$

Sum of electronic and zero-point Energies $=-1862.150372$

Sum of electronic and thermal Energies $=-1862.113458$

Sum of electronic and thermal Enthalpies $=-1862.112514$

Sum of electronic and thermal Free Energies $=-1862.216447$

Table S4. Cartesian coordinates $(\AA)$ of the $\left[\mathrm{GdL6}\left(\mathrm{H}_{2} \mathrm{O}\right)\right]^{+} \cdot 2 \mathrm{H}_{2} \mathrm{O}$ system optimized with DFT calculations.

C, $0,-0.5864688572,-0.6445029199,-2.7919587635$

$\mathrm{H}, 0,-0.3977640851,-0.6491593584,-3.8778586758$

$\mathrm{H}, 0,-1.6095648109,-0.2873381171,-2.6470030988$

C, $0,-0.4076263167,-2.0736234574,-2.2704089353$

$\mathrm{H}, 0,-1.0440373334,-2.7509379879,-2.8604798695$

$\mathrm{H}, 0,0.6284206738,-2.3840509655,-2.4482309594$

C, $0,0.0871455296,-3.3784844487,-0.2552233652$

$\mathrm{H}, 0,1.082213241,-3.3716785187,-0.7099124632$

$\mathrm{H}, 0,-0.3843167482,-4.3350012313,-0.5331327088$

C, $0,0.2083313117,-3.3128180232,1.2690029979$

$\mathrm{H}, 0,-0.7850698731,-3.33967534,1.7306128461$

$\mathrm{H}, 0,0.7486991887,-4.2094908515,1.6094546564$

C, $0,2.3374930913,-2.1273485469,1.7386483872$

$\mathrm{H}, 0,2.7252825522,-3.0822629471,2.123644152$

H, $0,2.6958559934,-1.322561611,2.394506058$

C, $0,2.8727214851,-1.8894237635,0.3473205647$

C, $0,4.0296480503,-2.5091081308,-0.096181767$

$\mathrm{H}, 0,4.5780007102,-3.1718630753,0.5685661566$

C, $0,4.4457662717,-2.2905487903,-1.4026851474$

H,0,5.3428062056,-2.773616394,-1.7843155266

C, $0,3.6875947185,-1.4722353369,-2.2213975731$

H,0,3.9627575767,-1.2978213933,-3.2589304705 
C, $0,2.5458630628,-0.8739611963,-1.6973717235$ C, $0,1.7331894788,0.0566373629,-2.5638437276$

$\mathrm{H}, 0,1.7374005129,-0.3139795181,-3.6002807232$ $\mathrm{H}, 0,2.2671970584,1.0145005941,-2.5792197513$ C, $0,0.0009626397,1.7047716972,-2.3563715015$ $\mathrm{H}, 0,-1.0568700409,1.8631341085,-2.1015754712$ $\mathrm{H}, 0,0.1373071434,1.980646728,-3.4136133552$ C, $0,0.8649449671,2.5784315086,-1.4617892391$ C, $0,1.2810412642,3.8588326559,-1.800986202$ $\mathrm{H}, 0,1.0077994503,4.2874331361,-2.7622482408$ C, $0,2.0530474712,4.569793169,-0.8887125571$ $\mathrm{H}, 0,2.3961277021,5.5731091856,-1.1323358735$ C, $0,2.3776515437,3.9961630041,0.3342192086$ $\mathrm{H}, 0,2.9650480124,4.5142709535,1.0869706317$ C,0,1.9132629987,2.7175222792,0.5951807814 C, $0,2.1273889044,2.0344839424,1.9481398907$ C, $0,-2.1318002647,-2.5197232812,-0.612321507$ $\mathrm{H}, 0,-2.2773604192,-2.863047793,0.4210599696$ $\mathrm{H}, 0,-2.4678098602,-3.3290942175,-1.2791274653$ C, $0,-3.0044882674,-1.3008194324,-0.7748878435$ C, $0,-4.3058788387,-1.3751831667,-1.2566756722$ $\mathrm{H}, 0,-4.701014716,-2.3237716176,-1.6121298084$ C, $0,-5.0796665189,-0.2233376893,-1.2663275784$ $\mathrm{H}, 0,-6.1004900106,-0.2528216245,-1.6415528815$ C, $0,-4.5400808932,0.9633378126,-0.7848976332$ $\mathrm{H}, 0,-5.0999574179,1.8936908029,-0.7501212362$ C, $0,-3.2312833361,0.9511218972,-0.3342403165$ C, $0,-2.5671470636,2.2003936959,0.2547017333$ $\mathrm{N}, 0,0.3414827976,0.2865343107,-2.1125844003$ $\mathrm{N}, 0,-0.6939439158,-2.2418476775,-0.8173557861$ $\mathrm{N}, 0,0.871925498,-2.0859505211,1.7556361336$ $\mathrm{N}, 0,2.1547362873,-1.070839311,-0.4379022016$ $\mathrm{N}, 0,1.2022103926,2.0334566553,-0.2941125784$ $\mathrm{N}, 0,-2.4806009311,-0.1517178423,-0.3511470269$ $\mathrm{O}, 0,1.4700588356,0.932586894,2.097204325$ $\mathrm{O}, 0,2.8520925621,2.5662135862,2.7719404863$ $\mathrm{O}, 0,-1.3623194336,2.0170964396,0.6300299087$ $\mathrm{O}, 0,-3.2252509193,3.2320586066,0.3172964229$ $\mathrm{O}, 0,-1.5320390445,-0.7087740667,2.3193973462$ Gd, $0,-0.0467253454,-0.0183078533,0.4950279965$ $\mathrm{H}, 0,0.590532688,-1.9274183761,2.7235700912$ $\mathrm{H}, 0,-1.1520049833,-0.6456397678,3.2159604225$ $\mathrm{H}, 0,-2.5126993702,-0.6465512524,2.3417379095$ $\mathrm{O}, 0,-4.2232589246,-0.7274047589,2.1497121331$ $\mathrm{H}, 0,-4.7184583938,0.0699571997,1.9353485235$ $\mathrm{H}, 0,-4.7397946907,-1.1980194704,2.8116139957$ $\mathrm{O}, 0,0.4358554995,-0.4898089588,4.1602925846$ $\mathrm{H}, 0,0.6037687487,-0.3507336677,5.0960099513$ $\mathrm{H}, 0,0.967867505,0.1556620434,3.6499333612$

$\mathrm{E}(\mathrm{RM} 11)=-1862.7180594$ Hartree Zero-point correction $=0.572486$

Thermal correction to Energy $=0.609972$

Thermal correction to Enthalpy $=0.610917$

Thermal correction to Gibbs Free Energy $=0.505372$

Sum of electronic and zero-point Energies $=-1862.145574$ 
Sum of electronic and thermal Energies $=-1862.108087$

Sum of electronic and thermal Enthalpies $=-1862.107143$

Sum of electronic and thermal Free Energies $=-1862.212688$ 